\title{
A Novel Approach to Reduction of Frictional Losses in a Heavy-Duty Diesel Engine by Reducing the Hydrodynamic Frictional Losses
}

\author{
Staffan Johansson, ${ }^{1}$ Per H. Nilsson, ${ }^{2}$ Robert Ohlsson, ${ }^{3}$ and Bengt-Göran Rosén ${ }^{4}$ \\ ${ }^{1}$ Vehicle Engineering, Volvo Group Trucks Technology, 40508 Gothenburg, Sweden \\ ${ }^{2}$ Advanced Technology \& Research, Volvo Group Trucks Technology, 41288 Gothenburg, Sweden \\ ${ }^{3}$ Powertrain Engineering, Volvo Group Trucks Technology, 40508 Gothenburg, Sweden \\ ${ }^{4}$ SET, Halmstad University, P.O. Box 823, 30118 Halmstad, Sweden \\ Correspondence should be addressed to Staffan Johansson; pusj@hotmail.com
}

Received 29 September 2016; Accepted 26 February 2017; Published 9 May 2017

Academic Editor: Yuansheng Jin

Copyright (C) 2017 Staffan Johansson et al. This is an open access article distributed under the Creative Commons Attribution License, which permits unrestricted use, distribution, and reproduction in any medium, provided the original work is properly cited.

An important parameter in the reduction of fuel consumption of heavy-duty diesel engines is the Power Cylinder Unit (PCU); the PCU is the single largest contributor to engine frictional losses. Much attention, from both academia and industry, has been paid to reducing the frictional losses of the PCU in the boundary and mixed lubrication regime. However, previous studies have shown that a large portion of frictional losses in the PCU occur in the hydrodynamic lubrication regime. A novel texturing design with large types of surface features was experimentally analyzed using a tribometer setup. The experimental result shows a significant reduction of friction loss for the textured surfaces. Additionally, the textured surface did not exhibit wear. On the contrary, it was shown that the textured surfaces exhibited a smaller amount of abrasive scratches on the plateaus (compared to the reference plateau honed surface) due to entrapment of wear particles within the textures. The decrease in hydrodynamic friction for the textured surfaces relates to the relative increase of oil film thickness within the textures. A tentative example is given which describes a method of decreasing hydrodynamic frictional losses in the full-scale application.

\section{Introduction}

Tremendous demands are put on the combustion engines of today. A significant parameter, perhaps the most significant parameter within engine development, is the reduction of fuel consumption and $\mathrm{CO}_{2}$ emission. Reducing frictional losses in the combustion engine means a reduction in $\mathrm{CO}_{2}$ emission. The largest contributor to frictional losses in the engine is the Power Cylinder Unit (PCU); around 50\% of the total frictional losses in the engine can be attributed to the PCU [1-4].

Much attention, from both academia and industry, has been paid to reducing the frictional losses in the boundary and mixed lubrication regime [5-8]; however, previous studies $[9,10]$ have shown that a large portion of the frictional losses in the engine occur in the hydrodynamic lubrication regime. There are several known techniques for reducing the hydrodynamic losses; however, although a reduction can be effected, there are also disadvantages:

(i) Viscosity of the engine oil is the dominating parameter in the hydrodynamic lubrication regime [11]. Reducing the viscosity of the engine oil decreases the hydrodynamic losses but could increase the frictional losses in the boundary and mixed lubrication regime [12], possibly causing an increase in wear.

(ii) Previous analysis has shown that, in the contact between the oil control ring and the cylinder liner, the main part of the surface significant for controlling friction, both hydrodynamic and mechanical [10], is the plateau part of the cylinder liner surface. The majority of the hydrodynamic friction losses occur at the midstroke region, because the highest piston 
velocity is achieved at this position [13]. An increase in the plateau roughness in the midstroke region would decrease hydrodynamic friction; however, the ever present smoothening of plateaus during running could decrease the initial effect of rougher plateaus; it is also possible that mechanical friction would increase with increased plateau roughness.

The aim of this study was to decrease the hydrodynamic losses of the PCU (Power Cylinder Unit) by means of surface texturing.

There are relatively few experimental studies analyzing the reduction of hydrodynamic friction losses for sliding line contacts that do not involve properties related to oil viscosity. It is possible to decrease the hydrodynamic frictional losses by applying surface texturing; a few examples of this are as follows:

(i) Qiu and Khonsari [14] analyzed the frictional behavior of elliptical and circular dimples in the hydrodynamic lubrication regime using an experimental tribometer setup. This experimental setup was meant to mimic the behavior of a laser textured piston ring. The result showed large frictional improvements with surface texturing; however, since the piston rings in the engine pass through all lubrication regimes, applying texturing on the piston rings might not prove ideal for a HD diesel engine. Also, the measured friction coefficient, up to 3 or even 4 , does not mimic the friction in the engine. If the friction coefficient would prove to be of the suggested magnitude, much larger differences would be expected at midstroke compared to reversal zones [15].

(ii) Costa and Hutchings [16] analyzed the frictional behavior of several different types of surface textures in reciprocating tribometer experiments. Here, it was determined that surface textures with larger valley width than the axial Hertzian contact length gave smaller film thicknesses compared to surfaces without textures. However, only small frictional differences were measured between different texture types. In the experiments, a reciprocating frequency of $0,55 \mathrm{~Hz}$ was used, and the stroke length was $22 \mathrm{~mm}$. This gives an average sliding speed of approximately $0,024 \mathrm{~m} / \mathrm{s}$ which could be regarded as too small for an accurate representation of PCU components.

(iii) Podgornik et al. [17] completed an experimental study in which the frictional effects of different types and sizes of textures in full film lubrication were examined in tribometer experiments. The results from this study suggest that friction can be reduced in the hydrodynamic lubrication regime by the use of textured surfaces.

Previous analysis has shown that the main part of the surface significant for controlling friction is the plateau part $[9,10,18$, 19] and that the valley part of the surface plays no significant role. The result from the literature survey however suggests a possibility of using textures also for the control of the viscous friction losses and a hypothesis tested in this study was formulated based on the assumption that a texture with a valley geometry larger both laterally and vertically than previously reported traditional cylinder liner concepts would constitute a texture able to decrease the hydrodynamic friction losses.

The design parameters of the texturing were based on the following prerequisites:

(i) Large Sized Features. Since no correlation between surface parameters describing the valley and friction was found in previous studies $[9,10,18]$, it was determined to analyze textures with a much larger geometry, in width, height, and depth, compared to the previously analyzed surface features (in comparison with the width, height, and depth of honing grooves; a schematic view of these geometries can be seen in Figures 3-5 in a previous study [10]).

(ii) Closed Circular or Elliptical Textures. The texturing would have to consist of elements that would extend from the plateau surface into the material, as closed void volumes. No extruding parts originating from the texture which could accelerate wear were desired. Closed void volumes as opposed to open volumes similar to traditional honing grooves were preferable to minimize the total oil transport by minimizing the oil transport within the textures [20], thus minimizing a possible increase in oil consumption caused by "open void channel” oil transport.

(iii) A Significant Texture Fraction of the Total Area. The area covered by the textures should be significant to obtain and test a significant difference in texture area coverage compared to the reference surface. Texturing area coverage of 30-35\% was initially selected for this study. It is assumed that a significantly larger cover ratio would increase the effect of boundary lubrication and a significantly smaller cover ratio would not make the effect more difficult to detect.

The frictional properties of textured surfaces were evaluated using a reciprocating tribometer. Using a tribometer presents the opportunity to conduct isolated analysis of engine components and is a common procedure for analysis of frictional effects and the durability of PCU components [21, 22].

\section{Experimental Methods}

2.1. Manufacturing of Textured Samples. A five-axis digitally automated computer numerical control milling machine (CNC) was used to machine the texturing pattern directly on the cylinder liner samples. Samples were cut out from a production cylinder liner; the axial length of the samples was $50 \mathrm{~mm}$ and the tangential width was $10 \mathrm{~mm}$. The milling operation in which a flat ended tool was used gave a sharp angle between texture and plateau surface. Two different protrusion depths were machined: $20 \mu \mathrm{m}$ and $100 \mu \mathrm{m}$ (termed T20 and T100 further on in the article); both textures had the same elliptical shape with the minor axis of $2 \mathrm{~mm}$ and the major axis of $3 \mathrm{~mm}$. 


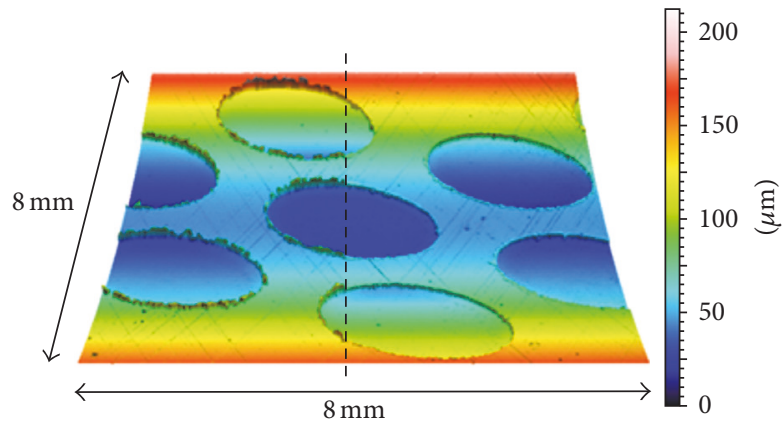

FIGURE 1: Illustration of the removal of the textures edge defects. The dotted line represents the reversal zone of the oil control ring; to the right of this line, the textures were removed in an initial experimental step.

A previous study [23] has shown that it is possible to decrease hydrodynamic frictional losses using a textured pattern with a surface lay which is parallel to the sliding motion. However, using a surface with a surface lay which is parallel to the sliding direction will decrease the generation of hydrodynamic pressure and decrease the oil film thickness between the piston ring and the cylinder liner [24], and thus the orientation/lay of the textures of 20 degrees in reference to the direction of motion was selected in this analysis.

The milling operation causes sharp edges or "burr" at the boundary of each texture element. Since this defect causes additional wear particles, it was decided to remove the sharp edges before the experiments. By running each sample for five minutes using the experimental input parameters of the center point of the DoE setup, the burrs were effectively removed; this is exemplified in Figure 1. This running in stage was carried out using sample material (oil control rings and engine oil) that was not used in further experimentation. The running-in stage is performed on all samples, both textured and untextured.

2.2. Tribometer. A tribometer test setup was used to quantify the frictional properties of reference and textured surfaces; a schematic overview of the tribometer is shown in Figure 2. In the tribometer experiment, oil was continuously fed from the piston ring sample holder to the inner diameter of the oil control ring and into the gap between the two beams in the oil control ring. The oil was supplied using a peristaltic pump; $4,8 \mathrm{~mL} / \mathrm{min}$ was continuously fed to the contact between the piston ring and the cylinder liner by injecting oil from the piston ring sample holder to the inner diameter at the position between the two beams of the piston ring. The continuous supply of oil with the said amount ensured fully flooded contact at all DoE cycle steps. The oil used was fully formulated 20W50 engine oil. The stroke length in the tribometer was set to $30 \mathrm{~mm}$.

In the tribometer, the reference cylinder liner surface, REF, and two different textured surfaces, T20 and T100, were evaluated. The opposing surface was a coil spring loaded twopiece oil control ring with two beams and standard beam width; to ensure conformability, a complete piston ring was
TABLE 1: Overview of input parameters of test cycle steps.

\begin{tabular}{lcccc}
\hline $\begin{array}{l}\text { Test cycle } \\
\text { step }\end{array}$ & $\begin{array}{c}\text { Time } \\
(\mathrm{min})\end{array}$ & $\begin{array}{c}\text { Temperature } \\
\left({ }^{\circ} \mathrm{C}\right)\end{array}$ & $\begin{array}{c}\text { Reciprocating } \\
\text { frequency } \\
(\mathrm{Hz})\end{array}$ & $\begin{array}{c}\text { Load } \\
(\mathrm{N})\end{array}$ \\
\hline 1 & 60 & 33 & 14 & 22 \\
2 & 30 & 23 & 10 & 12 \\
3 & 30 & 23 & 18 & 12 \\
4 & 30 & 43 & 10 & 12 \\
5 & 30 & 43 & 18 & 12 \\
6 & 30 & 33 & 14 & 22 \\
7 & 30 & 23 & 10 & 32 \\
8 & 30 & 23 & 18 & 32 \\
9 & 30 & 43 & 10 & 32 \\
10 & 30 & 43 & 18 & 32 \\
11 & 30 & 33 & 14 & 22 \\
\hline
\end{tabular}

used in the experiments. The tribometer experiment was repeated four times for each surface. The input signals in the experiment were reciprocating frequency, temperature, and load; these signals were varied according to a Design of Experiment (DoE) setup (see Table 1) with high and low levels of all three input parameters. To verify the stability of the experiment over time, three parameter center points were added, as starting point, after half of the experimental points and at the end of the DoE setup. The measured output parameters were friction force and resistivity coefficient. Friction force was measured using piezoelectric transducers; resistivity coefficient was measured by quantifying the difference of the electrical contact resistivity between a resistor (with fixed level) and the electrical contact resistivity of the contact between the piston ring and the cylinder liner. The series resistor value was chosen to give the best discrimination of resistive coefficient comparing the value at the reversal and the value at midstroke for the reference material. In this study, the electrical resistance was measured using a voltage divider with the fixed resistor in series with the contact resistance. The resistive coefficient is not the electrical resistance but is actually the voltage drop over the tribocontact and is consequently inversely proportional to the electrical resistance. Electrical resistance is proportional to the area of contact [25], and the resistive coefficient is thus inversely proportional to the amount of contact. Comprehensive details of the experimental setup and quantification of input and output signals can be found in $[9,10]$.

2.3. 3D Profilometry. Surfaces were measured using CCP (Chromatic Confocal Probe) [26]. The complete surface of the cylinder liner sample, $48 \mathrm{~mm} * 10 \mathrm{~mm}$, was measured using point spacing of $10 \mu \mathrm{m}$, and the surface was measured before and after the experiment. To calculate geometric properties of surface features, it is common to remove the form prior to feature computation. Commonly, second-order polynomial form removal is sufficient for a cylinder liner surface; however, it was noticed that, for the textured surfaces, this type of form removal generated an undesired artificial 


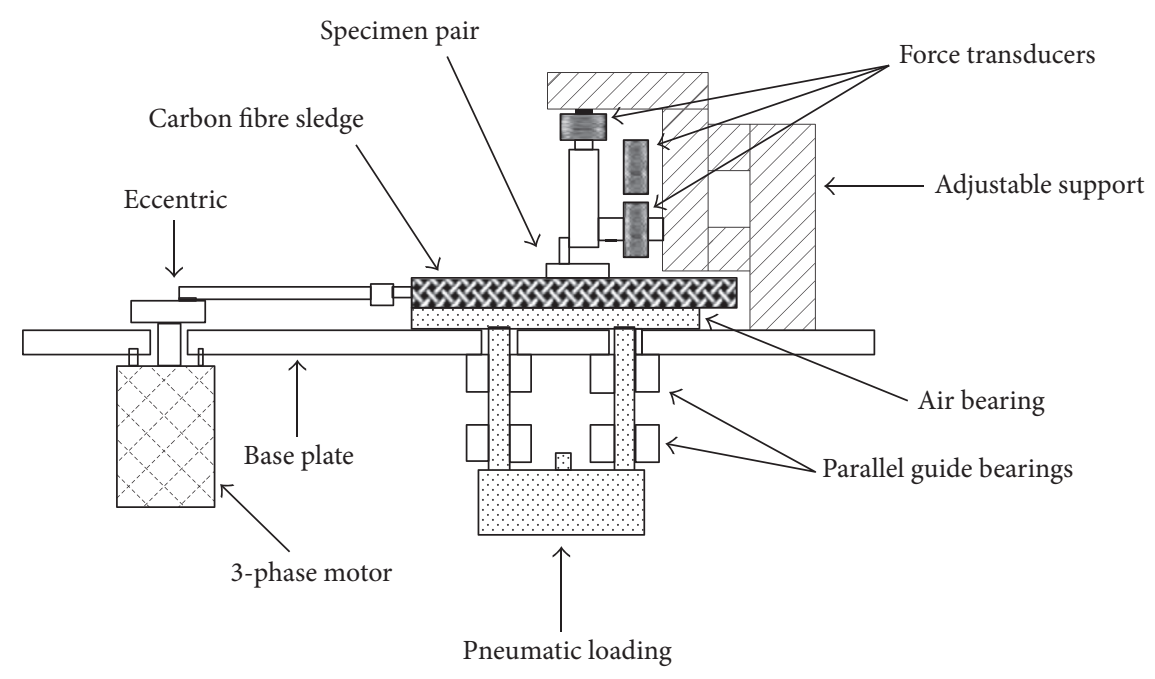

FIGURE 2: Schematic overview of the reciprocating eccentric tribometer.

form. To obtain a representative value of the dimensions of the textures, the surface form for the textured surfaces was removed with the following operations:

(1) Substitution of missing points by defined smooth shape (evaluation software: Mountains Map ver. 5.1, product of Digital Surf, Besançon, France).

(2) Second-order polynomial form removal from the original surface measurement.

(3) Edge detection technique (grain analysis modulus (evaluation software: Mountains Map ver. 5.1, product of Digital Surf, Besançon, France)) to define edges between the textures and the plateau surface.

(4) Extraction of grains; only grains belonging to the texture elements were selected.

(5) Masking of the texturing elements using the output of grain analysis. The texturing is thus removed from the surface (the datum of the texturing elements was replaced with missing points).

(6) Second polynomial form removal on the plateau surface (textures were removed using grain analysis in a previous step); the output from this step is the $2 \mathrm{D}$ form.

(7) Subtraction of the surface form generated in 6 with the surface obtained in 2 .

Using the computational steps above, a surface without artificial form effects caused by the textures could be obtained; the geometry of each texturing element could thus be analyzed explicitly.

In order to quantify the wear depth, the surface measured before the experiment was subtracted from the surface measured after the experiment using the unworn part of the cylinder liner sample as reference for the absolute height datum.

\section{Results}

3.1. 3D Profilometry: Evaluation of Wear and Texture Geometry. The geometry of the texturing elements was evaluated using the grain analysis modulus in Mountains Map (see Figure 3). In the comparison between materials T20 and T100, it was found that the only difference in respect to texture geometry was obviously the depth of the textures; no other significant differences could be detected in the density of textures, the average maximum and minimum diameter, the average area density of the textures, the average texture orientation, and the average texture perimeter (for more information, see the Appendix). The angle at the boundary of the texture was difficult to quantify since the measurement technique is not capable of measuring sharp corners; a too high angle returns a missing point. After filling of the missing points, the angle was manually evaluated for several positions; the majority of the angular measurements were between $83^{\circ}$ and $85^{\circ}$.

No wear was detected in the evaluation of wear depth (subtraction of surfaces before and after the experiment). As an additional analysis of wear, the surfaces were analyzed under a light optical microscope after the experiment. In this analysis, abrasive scratches were detected on the plateau part of the reference surface; however, virtually, no abrasive scratches were detected on the plateau part of the textures surfaces (see Figure 4). In closer inspection of the texture elements, it was seen that the texture itself contained significant amounts of wear particles (Figure 5).

3.2. Tribometer: Evaluation of the Stability of Input Signals. To gain representative values for each surface, the validity of the input signals was quantified; the said input quantified signal can be seen in Figure 6. To gain better representation of the input signals, these are recalculated; sliding speed is calculated from reciprocating frequency; oil dynamic viscosity is calculated from temperature; and contact pressure is calculated from load according to a previous study [18]. 


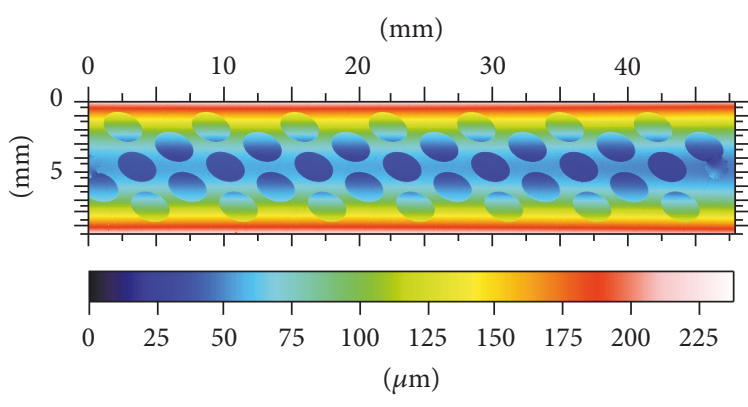

(a)

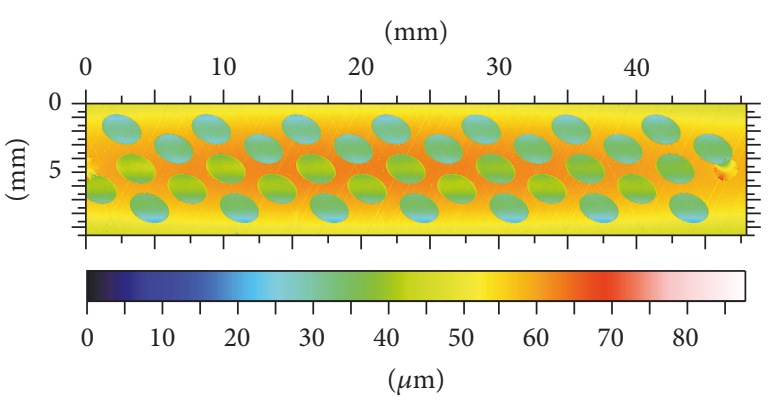

(b)

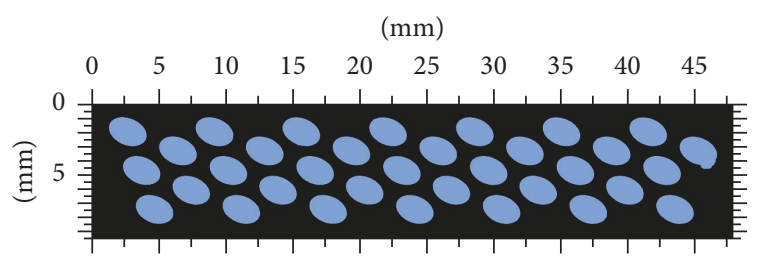

(c)

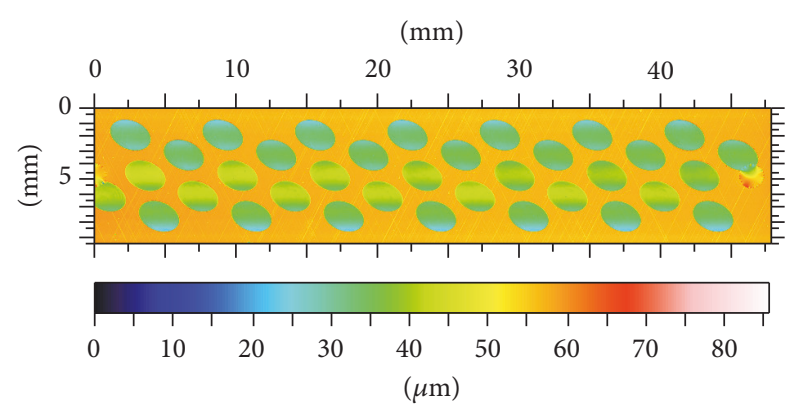

(d)

FIgURE 3: Example of form removal on a textured surface by removal of the significant texture prior to form removal and the consecutive adding of segmented features. (a) Original surface measurement. (b) Surface form removal by second-order polynomial extraction; it should here be noticed that this surface does not have a flat plateau area; much of the surface form remains after the first form removal step. (c) Grain analysis of textures in which texture elements are extracted. (d) Surface after second-order polynomial form removal based on grain analysis. It should here be noticed that the plateau part of the final surface does not have any residual form.

Performing the recalculation of input parameters also gives parameters which are independent of the test arrangement since sliding speed is dependent on stroke length, contact pressure is dependent on relative area of contact, and so forth.

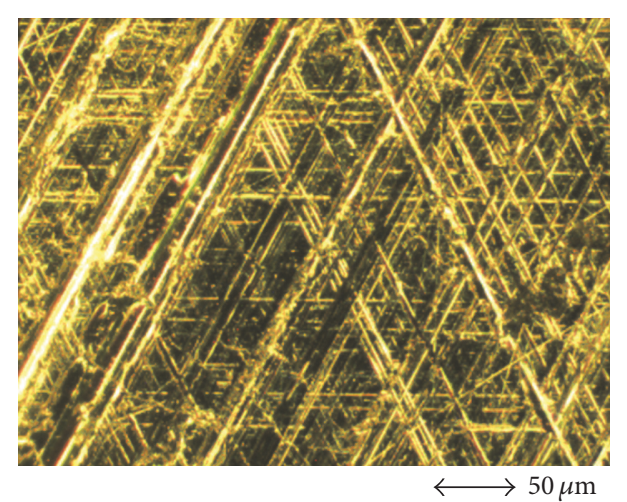

(a)

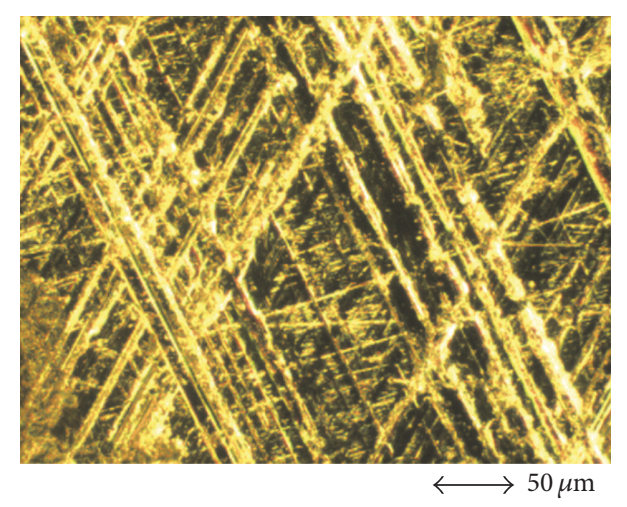

(b)

FIgURE 4: Microscope images after the tribometer experiment. (a) Reference material, example of axial abrasive scratches on plateaus. (b) T100: no axial scratches can be detected.

From the analysis of the input signals, it was detected that, for one of the experiments of T20 (T20-2), the dynamic viscosity is different from the other signals and for one of the experiments of T100 (T100-4) the contact pressure is different from the other measured signals; these two experiments are therefore removed in further evaluation.

3.3. Tribometer: Evaluation of Friction Coefficient and Resistive Coefficient. The experiments T20-2 and T100-4 were removed from this study; it should be noted that both of these experiments exhibited smaller values of friction coefficient compared to the average value for each surface texture. Figure 7 shows the measured friction coefficient for all experiments; in Figure 8, the average values of each surface are shown. Table 2 shows the standard deviation of the average friction coefficient as shown in Figure 8.

The resistive coefficient was measured in the tribometer experiment; Figure 9 shows the resistive coefficient for all experiments and in Figure 10 the average values of each surface are shown. Table 2 shows the standard deviation of the average resistive coefficient as shown in Figure 10.

3.4. Tribometer: Evaluation of Lubrication Regime and Experimental Output. For an illustrative analysis of different lubrication regimes, the cycle steps were plotted for each input 


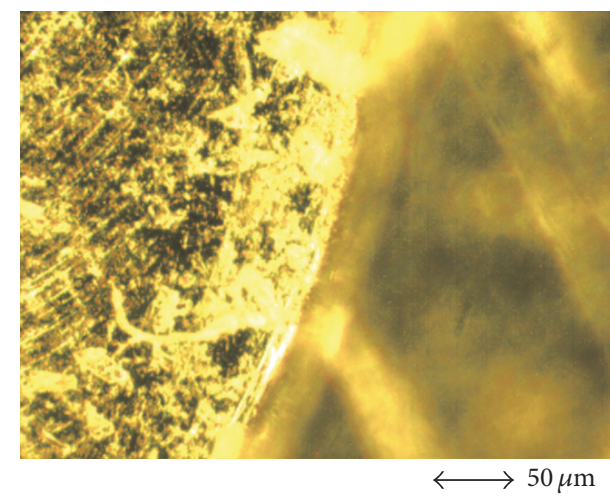

(a)

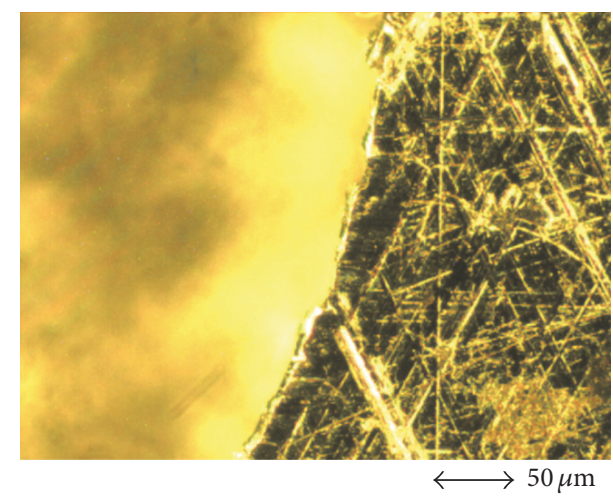

(b)

Figure 5: Microscope images after the experiment, T100. (a) Focus on the bottom part of the texture, wear particles trapped. (b) Focus on the plateau; this image shows the expected wear on the texturing boundary; however, no significant wear is detected on the neighbouring plateau.

TABLE 2: Average values of standard deviation of friction coefficient and resistive coefficient for experiments. T20 and T100 represent the values of standard deviation for the reduced set of experiments. T20* and T100* represent the values of standard deviation for all experiments, without reduction in the number of experiments.

\begin{tabular}{lcccrr}
\hline & REF & T20 & T20* & T100 & T100* \\
\hline Standard deviation of friction coefficient & 0.0169 & 0.0043 & 0.0042 & 0.0109 & 0.0111 \\
Standard deviation of resistive coefficient & 0.5880 & 0.4190 & 0.3556 & 0.1321 & 0.1176 \\
\hline
\end{tabular}

cycle step. What signifies the hydrodynamic lubrication regime is that friction increases for an increase in speed, an increase in oil viscosity, and a decrease in contact pressure. Each cycle step in the DoE setup is 30 minutes; to minimize the effect of transitions (e.g., thermal) between cycle steps, the values of friction coefficient are only calculated for the duration of 10-29 minutes within each cycle point. Each point in this statistical analysis represents the mean of all experiments for each surface.

On analyzing the lubrication regime transitions for the reference surface, it was shown that

(i) a shift towards the hydrodynamic regime is present for both increase in dynamic viscosity (as can be seen in Figure 11) and decrease in contact pressure (as can be seen in Figure 13);

(ii) a shift towards the hydrodynamic lubrication regime is present for low values of temperature (high level of viscosity), and a shift towards the boundary lubrication regime is present for high values of temperature (low level of viscosity).

On analyzing the lubrication regime transitions for the textured surfaces, it was shown that

(i) a shift towards the hydrodynamic regime is present for a decrease in contact pressure (as for the reference surface) (as can be seen in Figure 13);

(ii) a shift towards the hydrodynamic regime is present for an increase in dynamic viscosity for all cycle steps except for the cycle step with high level of load and low level of reciprocating frequency (similar to the reference surface, as can be seen in Figure 11);

(iii) a shift towards the hydrodynamic regime is present for an increase in sliding speed at low level of load and high level of reciprocating frequency (as can be seen in Figure 12); a shift towards the boundary lubrication regime is present for high values of temperature (as for the reference surface). For high level of load and low level of temperature, T20 and T100 show slightly different results where an increase in sliding speed shows a shift towards the boundary lubrication regime for T20 and a shift towards the hydrodynamic lubrication regime for T100.

The following conclusions can be drawn for the analysis of the frictional measurement and of the transitions of lubrication regime for different experimental points:

(i) The highest measured friction was found in experimental step number 3 which is a combination of high level of sliding speed, high level of dynamic viscosity, and low level of contact pressure; thus, the friction is the highest for contact with the most hydrodynamic lubrication condition.

(ii) The contact pressure at the investigated levels has the most significant impact on friction.

(iii) In general, the textured surfaces have the same frictional behavior as the reference surface; some 


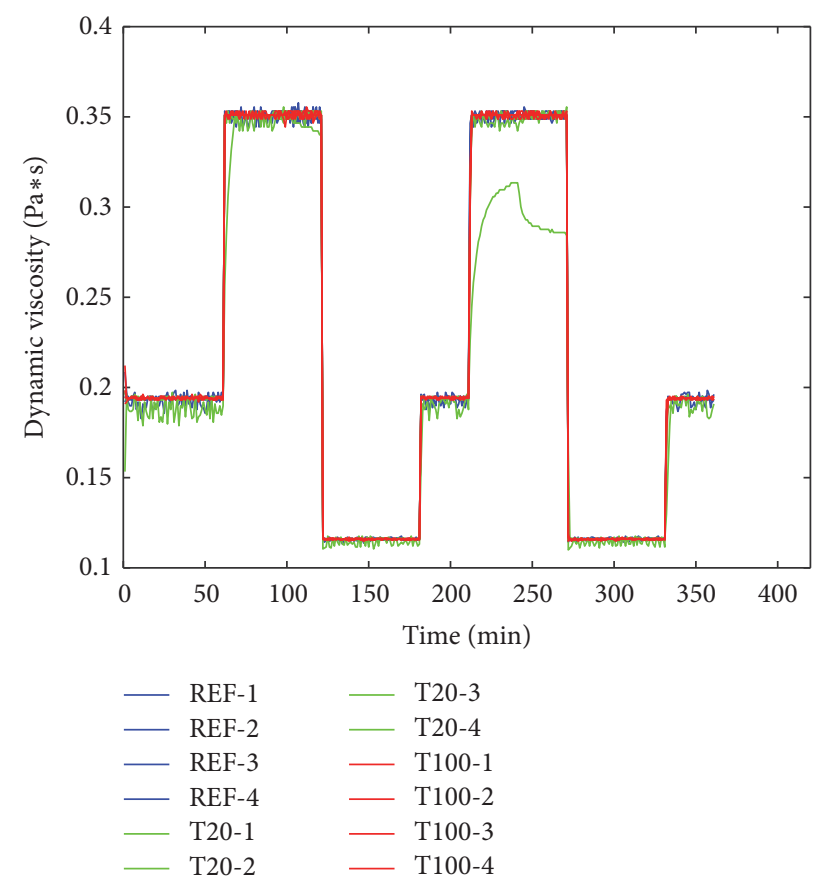

(a)

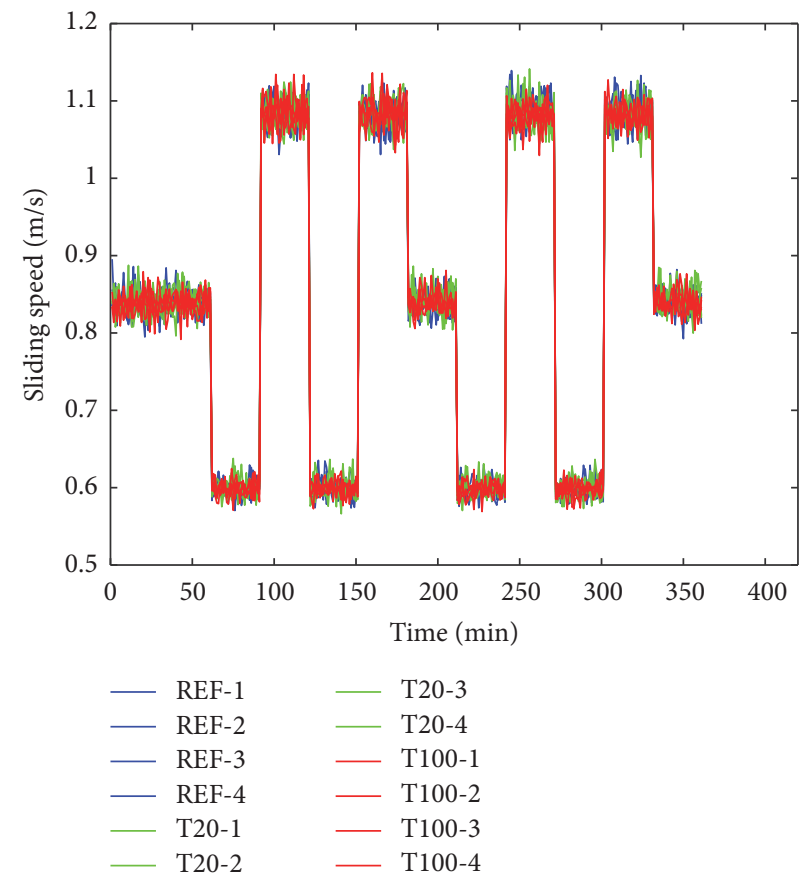

(b)

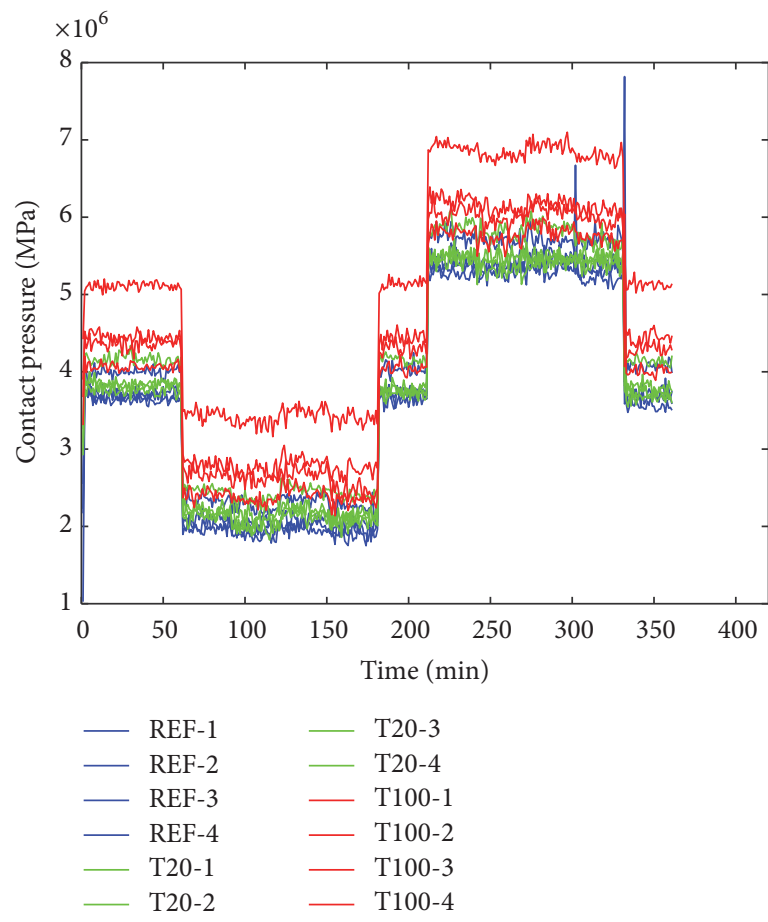

(c)

Figure 6: Measurement of input signals in experiments. (a) Dynamic viscosity. (b) Sliding speed. (c) Contact pressure.

differences are present for textured surfaces with shift towards the boundary lubrication regime; however, at low contact pressure and high viscosity, the friction increases with increased sliding speed for all investigated surfaces; thus, a shift towards the hydrodynamic lubrication regime is present for this contact condition for all surfaces, textured or untextured.

\section{Discussion}

4.1. Behavior of Oil Film Thickness and Textures. What causes the friction to decrease in sliding contact with textures even though a higher level of contact was measured for the textured surfaces? To visualize the interaction between two opposing surfaces in sliding motion in which one of these 

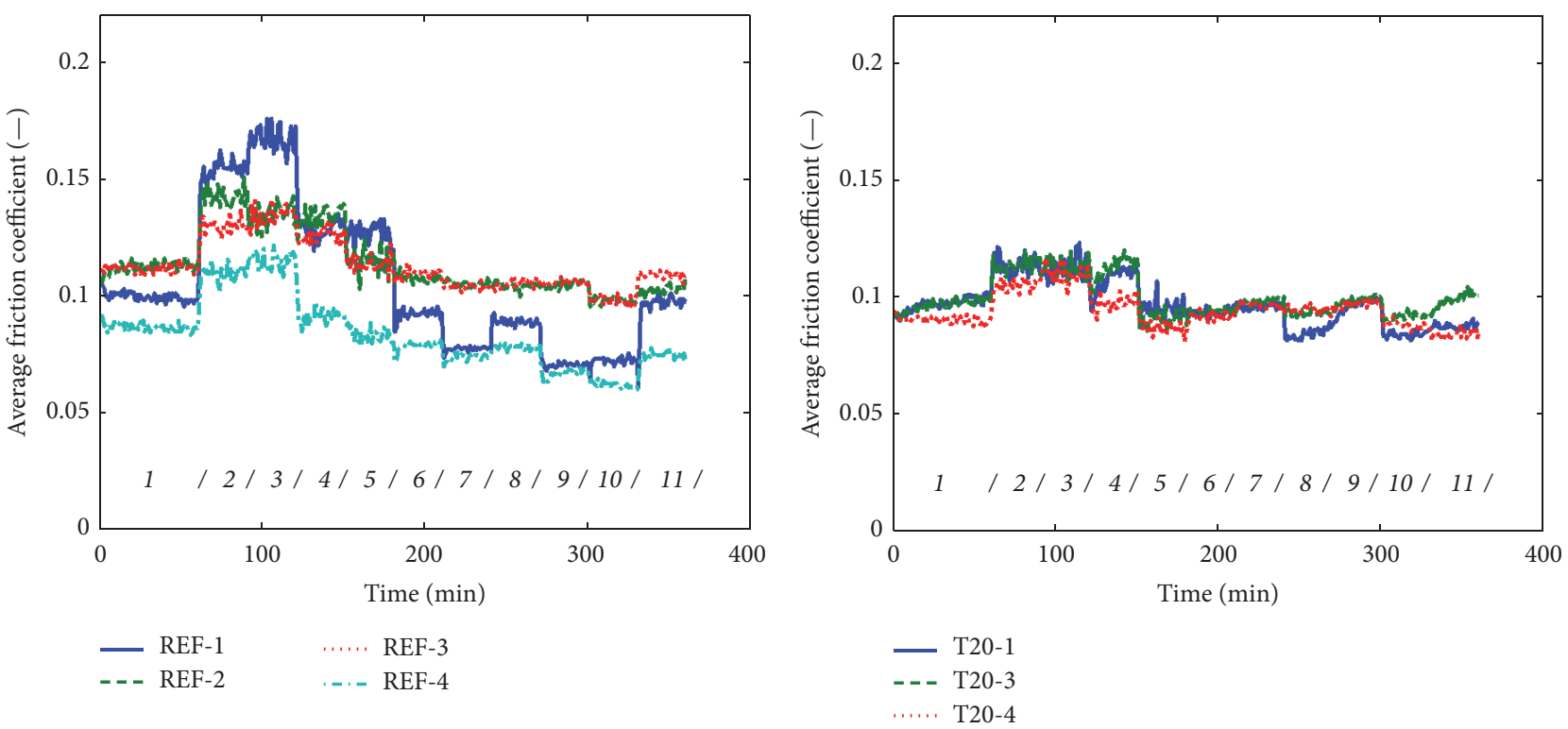

(a)

(b)

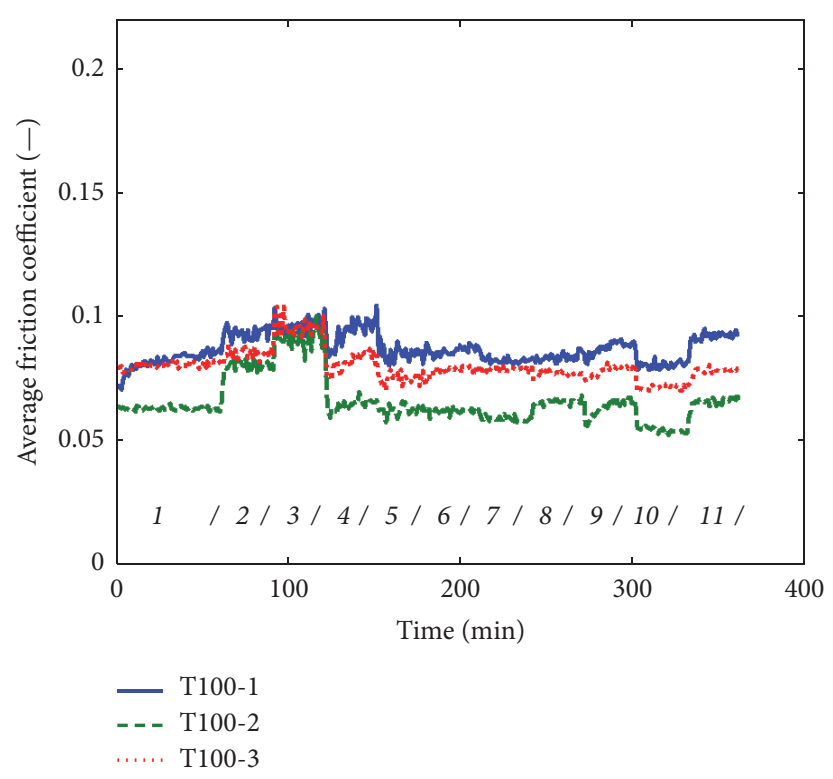

(c)

FIGURE 7: Measured friction coefficient for each experiment. The numbers above the $x$-axis (italics) indicate the duration of each experimental cycle step. (a) REF. (b) T20. (c) T100.

surfaces is textured, the problem has to be divided into two perspectives: either the contact is between the plateaus of the two surfaces (plateau of cylinder liner versus plateau of piston ring) or the contact is between the plateau part of the piston ring and the texture element of the textured surface (texture of cylinder liner versus plateau of piston ring). Equation (1) describes shear force, $F_{T}$, for two parallel planes fully separated by a Newtonian fluid. When a mating surface, for example, a piston ring, passes over a texture, the area, $A$, is also unaltered for the passage since the surface is not decreased or removed; there are still two parallel planes, although in the passage of a texture the planes are farther apart compared to the distance between the two plateaus of the mating surfaces. Hence,

$$
F_{T}=\frac{\eta v A}{h}=\eta S A .
$$

In an analysis of the oil viscosity, it is important to account for the non-Newtonian shear rate behavior of the engine oil. The shear rate is dependent on oil film thickness, $h$, and sliding velocity, $v_{0}$ (see (2)). The dynamic viscosity, $\eta$ or $\mu$, is dependent on the shear ratio; for low levels of shear rate, the value of viscosity is assumed to be that of zero shear, $\mu_{0}$, and for high levels of shear rate the value of viscosity is assumed 


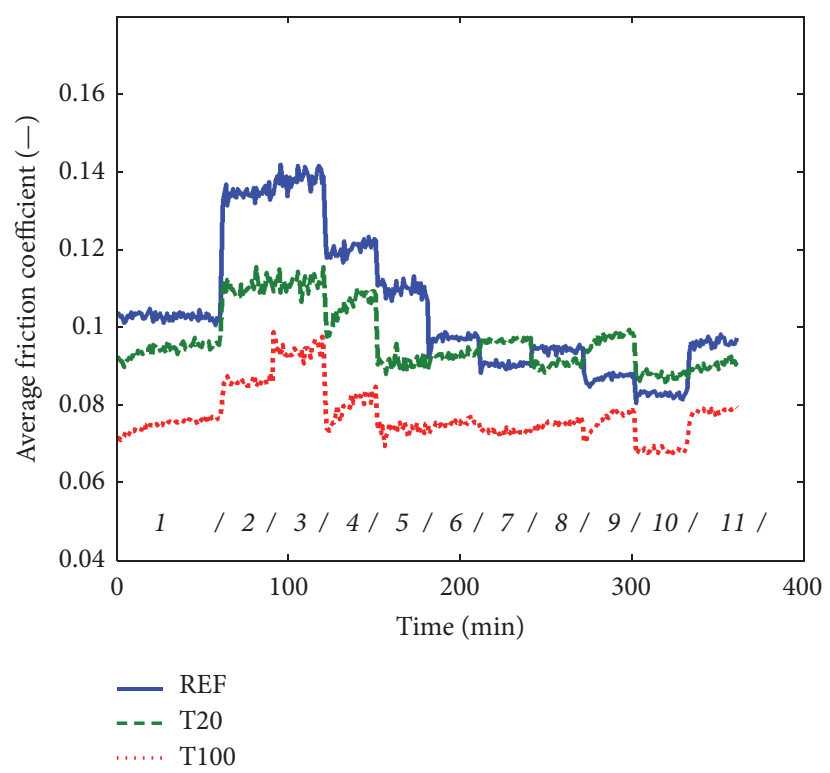

FIGURE 8: Measured friction coefficient, average of experiments for each surface type. The numbers above the $x$-axis (italics) indicate the duration of each experimental cycle step.

to be that of infinite shear, $\mu_{\infty}$ (see (3)). As was shown in the experimental study, the amount of contact increases for the textured surface compared to the reference surface. For passage of a texture, the oil film thickness increases and thus $\eta$ or $\mu$ increases; however, the oil film thickness decreases for passage of a plateau and thus $\eta$ or $\mu$ decreases. The effect of viscosity on shear force is however not believed to be highly significant since the decrease of dynamic viscosity for passage of plateau is partially cancelled out by the increase in dynamic viscosity for passage of a plateau. Therefore,

$$
\begin{aligned}
& S=\frac{v_{0}}{h}, \\
& \mu=\mu_{\infty}+\frac{\mu_{0}-\mu_{\infty}}{1+\gamma / \gamma_{c}} .
\end{aligned}
$$

In essence, there is no alteration of the area and it is believed that there is no significant alteration of the dynamic viscosity for a textured surface compared to the reference surface; there is however a significant increase in the oil film thickness of passage of a texture if the oil film thickness is considered as the entire depth of the texturing element.

The resistive signal increases for the textured surfaces which indicates that the amount of metal-to-metal contact increased for the textured surface compared to the reference surface (see Table 3 ); this shows that there is generally a thicker oil film $h_{\text {ref }}$ (see Figure 14) between the reference surface and the opposing surface compared to the oil film $h_{\mathrm{oT}}$ (oil film thickness outside of the texture) between the plateau of a textured surface and the opposing surface. However, for the textured surfaces and the passage of a texture, the oil film thickness is the same as the texture depth considering that the contact between the piston ring and the cylinder liner is fully flooded. The increase in metal-to-metal contact for the
TABLE 3: Average friction coefficient and average resistive coefficient for each surface type.

\begin{tabular}{lccc}
\hline Surface type & REF & T20 & T100 \\
\hline Average friction coefficient & 0,105 & 0,097 & 0,078 \\
Average resistive coefficient & 1,209 & 1,399 & 1,575 \\
\hline
\end{tabular}

textured surfaces is due to a decrease in the build-up of hydrodynamic pressure. There are two causes for loss of hydrodynamic pressure: firstly because of leakage of oil into the texture and secondly because less surface area is available for the generation of hydrodynamic pressure. The amount of metalto-metal contact is greater for T100 compared to T20, since the areas of the textures are practically the same; this means that the leakage of oil into the texture is greater for the T100 textured surface. A summary of the average values of friction coefficient and the average values of resistive coefficient for all experiments and DoE cycle steps can be seen in Table 3.

In the tribometer experiment, fully flooded conditions were withheld for all experimental conditions; this gives an oil film thickness five times larger for passage over a texture of the T100 surface considering that the texture depth is five times larger for T100 $\left(h_{\mathrm{iT} 100}\right.$ in Figure 14 , oil film thickness for passage of T100 texture) compared to T20 $\left(h_{\mathrm{iT} 20}\right.$ in Figure 14 , oil film thickness for passage of T20 texture). In this calculation of the very specific oil film thickness within textures, the possible reduction in oil film thickness obtained due to the reduction in hydrodynamic pressure (for the two textured cases) is not taken into account. The calculated average oil film thickness mentioned in this paper for textured surface area is the average separation for the two components: average separation for the textured part of the surface times the texturing area density combined with the average separation 

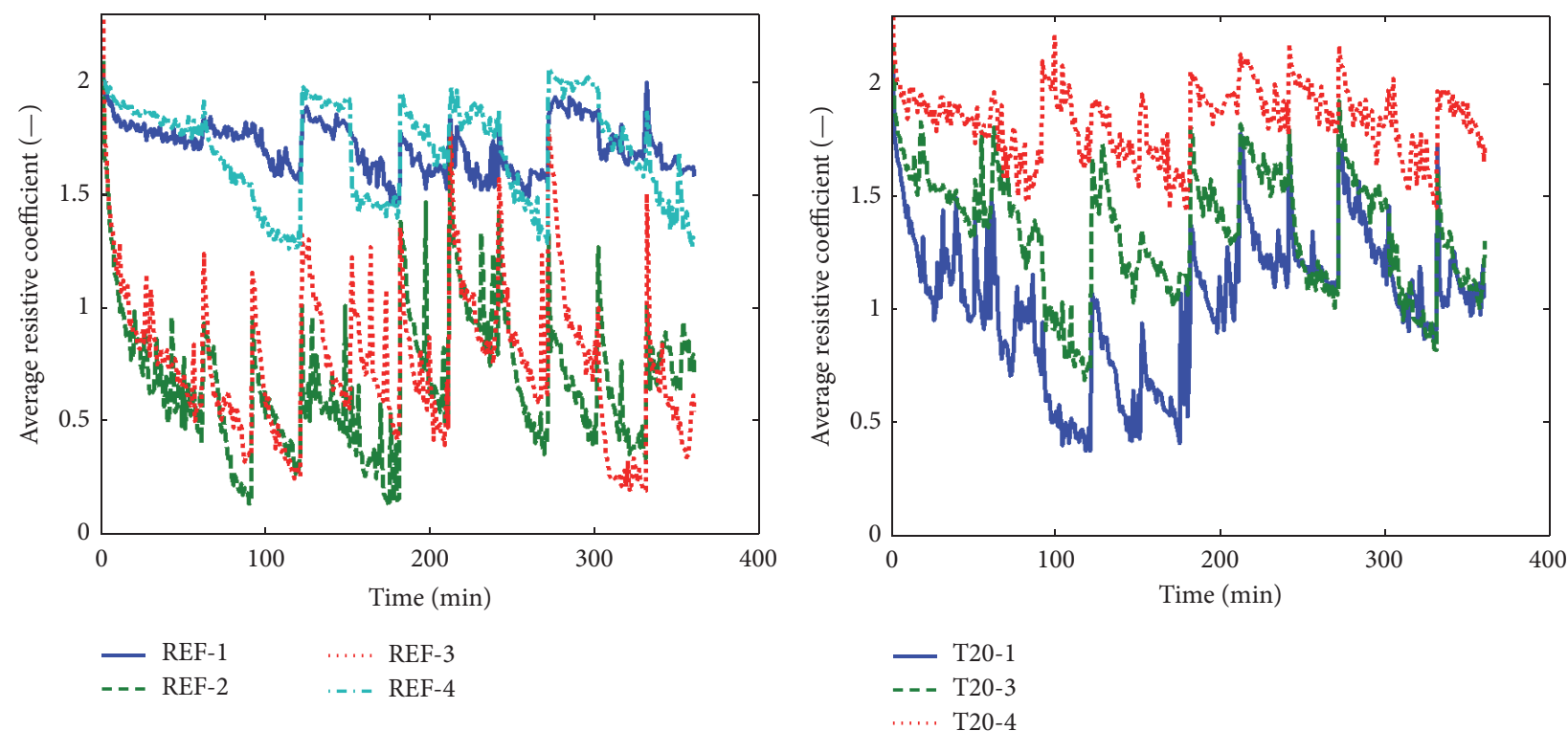

(a)

(b)

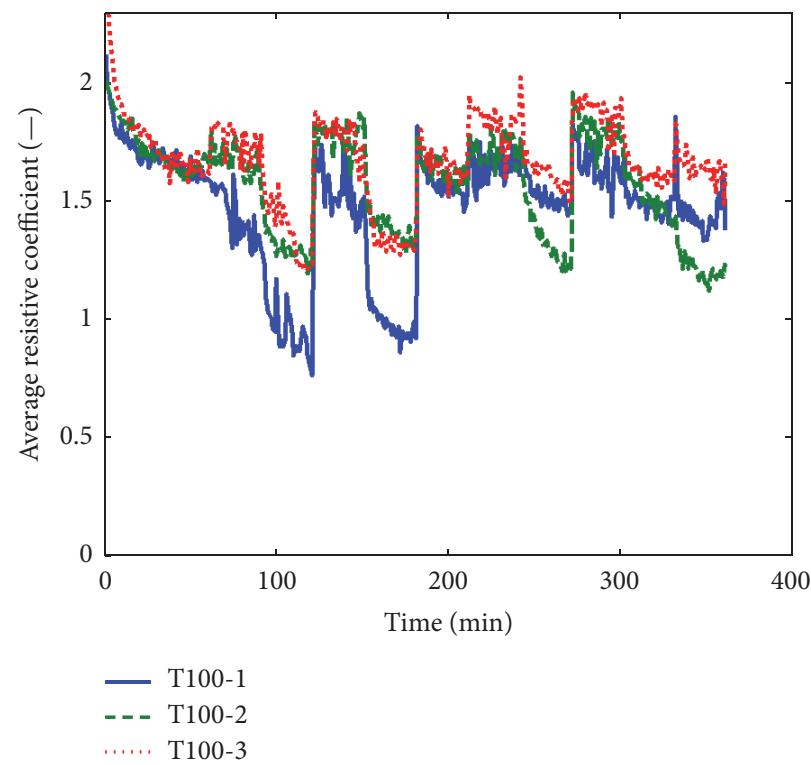

(c)

FIGURE 9: Measured resistive coefficient for each experiment. (a) REF. (b) T20. (c) T100.

for the plateau (nontextured) part of the surface times the plateau area density.

Since it is assumed that the oil transport from texture to plateau and from plateau to texture (in relation to the volume of the texture) will be small, the oil within the texture will be forced to recirculate; this is why there is a difference in the flow profiles for passage of textures compared to flow profiles for passage of plateau in Figure 14. The surface T20 exhibited a larger friction coefficient for some experimental cycle steps in which a high load was used (e.g., cycle step 9); the reason for this is believed to be that the increase in boundary friction for passage of a plateau was greater than the decrease in viscous losses for passage of texture, thus combined creating a higher friction than that of the reference surface.

4.2. Texture Properties Applicable to a Tribosystem in Hydrodynamic Lubrication. Textured surfaces with elements of similar geometry to the ones investigated in this paper can be applied on a tribosystem with reciprocating sliding with the aim of decreasing hydrodynamic friction. However, certain aspects should be considered. It is not optimal to put textures in the reversal zones of a tribosystem due to the following:

(i) The sliding speed is small at the reversal zones and thus the hydrodynamic friction losses are small. 


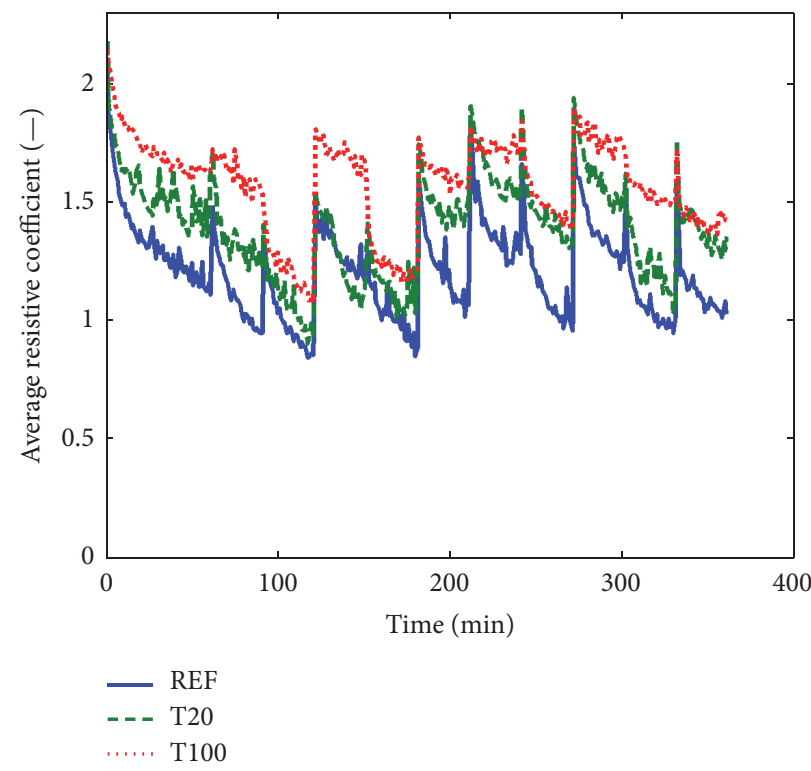

FIGURE 10: Measured resistive coefficient, average of experiments for each surface type.

(ii) If temperatures are high, the oil viscosity is low and thus the hydrodynamic friction losses are small.

(iii) If the contact pressure in the tribosystem is high, an addition of textures in severe tribological contact could increase wear [27]; thus, it is not regarded as beneficial to apply textures with similar dimensions as investigated in this study in the vicinity of the reversal zones.

The surface angle, which is the slope in the axial direction between the edge of the plateau surface and the bottom of the texture (for the textures shown in Figure 14(b), this angle is $90^{\circ}$ ), was high for the analyzed textures; this is here considered preferable since, with a high angle at the boundary, the oil film will be larger at a larger surface area. In perspective, this could be regarded as follows: either the counter body slides over a texture with high film thickness or it slides over the plateau surface to build up oil film between the two mating surfaces. The passage of texturing provides decreased hydrodynamic friction losses. The passage of a plateau provides oil film build-up between components in the tribosystem. To gain additional frictional improvement from a textured surface, it is important to produce a smooth surface on the plateaus to decrease the mechanical friction of the passage of a plateau.

The addition of the suggested surface textures increases the surface volume. An example of a sliding reciprocating tribosystem is the cylinder liner. In applying the knowledge to this system, it is important to analyze the effects on blowby and oil consumption. Hegemier and Stewart [28] analyzed the effects on blow-by and oil consumption for different types of cylinder liner surfaces, although the analyzed surfaces were different from the suggested surface texturing in this study. Hegemier and Stewart found that different surface finishes had a little effect on blow-by and that the dominating factor that controlled oil consumption was the amplitude of the plateau roughness. Still, it could be necessary to optimize the geometries of the piston rings for efficient control of blow-by and oil consumption; one suggestion in this optimization is to analyze the effects on blow-by and oil consumption with different designs of gas tight top rings [29].

Seki et al. have experimentally analyzed the oil film thickness (OFT) [30] between piston rings and the cylinder liner; the result in this study shows that OFT increases with sliding speed. The following is a tentative example of how friction could be reduced by applying surface textures.

We start by assuming that oil film thickness increases linearly with sliding speed (this is a generalization despite being not that different from the study carried out by Seki et al.) for a reference plateau honed cylinder liner. We also assume that a varying area density of uniform texturing elements (with the geometry of T100) is applied on a textured cylinder liner surface, excluding the reversal zones (at the position of 0-20 crank angle degrees and at the position of 160-180 crank angle degrees). In this example, we do not define a location on the stroke for a specific component; this should be seen more as a general description. The area density of this texturing increases linearly from 21 to 90 crank angle degrees and decreases linearly from 90 to 159 crank angle degrees. On the untextured part of the textured cylinder liner, we assume that the oil film thickness between the plateau surface of the cylinder liner and the piston ring is the same as for the reference cylinder liner. We also assume that the oil film thickness is the same for the textured cylinder liner compared to reference cylinder liner for crank angle degrees that have a smaller value of oil film thickness compared to the constant value of oil film thickness. By controlling the area density of the texturing, the oil thickness between the plateau of the cylinder liner and the piston ring does not increase for crank angle 21-159 but is maintained at a constant value for the textured surface, which in this tentative example varies between $20 \%$ and $50 \%$ (see 


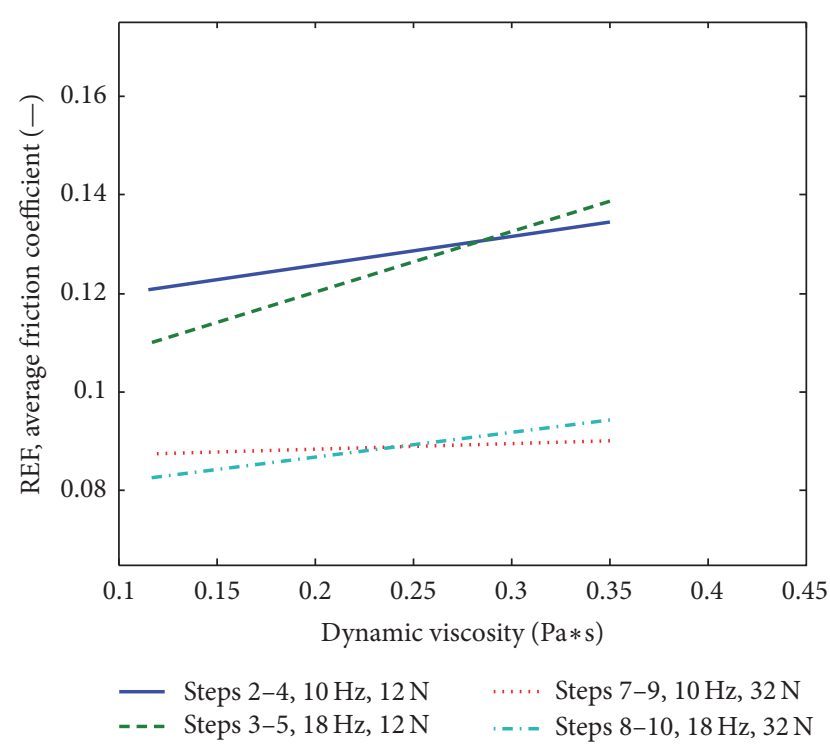

(a)

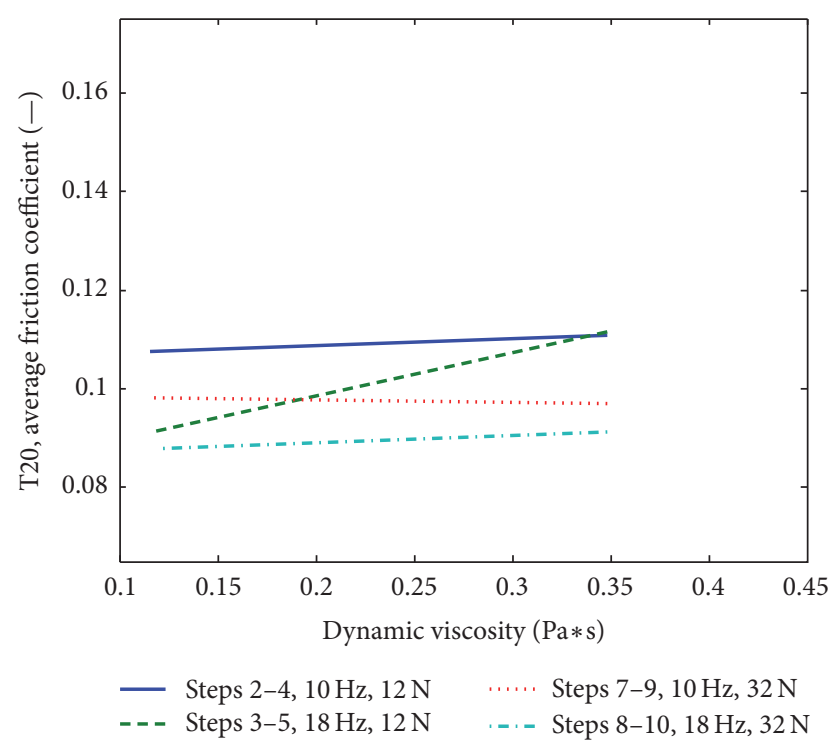

(b)

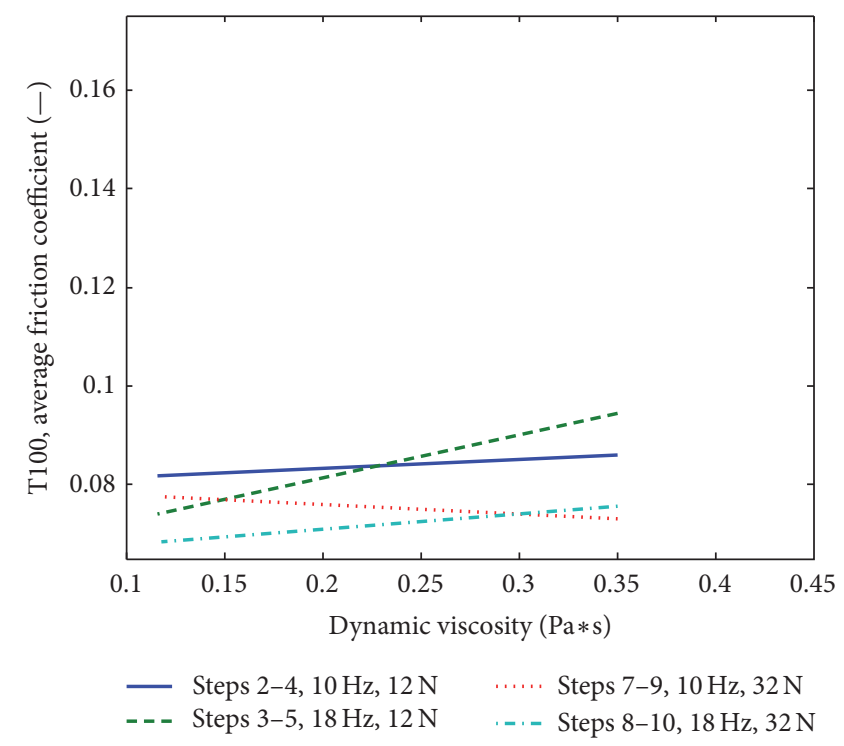

(c)

FIGURE 11: Evaluation of the different levels of DoE input parameters. The effect of dynamic viscosity on the friction coefficient. (a) REF. (b) T20. (c) T100.

Figure 15). The average oil film thickness for the textured surface including the oil film height within textures will thus be significantly higher than the oil film thickness for the reference surface; by this, it is possible to decrease the hydrodynamic friction.

In the example above, it is shown that the average oil film thickness with inclusion of the textures is greatly increased, and thus friction will decrease greatly according to (1). However, there is most likely a limit to which this equation is valid, assuming that viscous shear dependency on oil film thickness might in practice prove inaccurate for high values of oil film thickness. On the contrary, in the analysis of wet clutch engagement, the assumption that torque due to viscous shear is inversely proportional to film thickness is still considered valid for an oil film thickness of 0,001 inches $(25,4 \mu \mathrm{m})$ [31] and it has been determined that if the contribution of viscous shear is neglected in a computational model the comparison to experimental data will be incorrect [32].

Also, it cannot be expected that, in the passage from plateau to texture, the flow profile of the oil is instantly fully developed down to the bottom of the texture. In this study, the axial length of the textures is far larger than the axial length of the piston ring and the sliding speed is smaller than that in the engine; thus, it is likely that the effect of time dependency and 


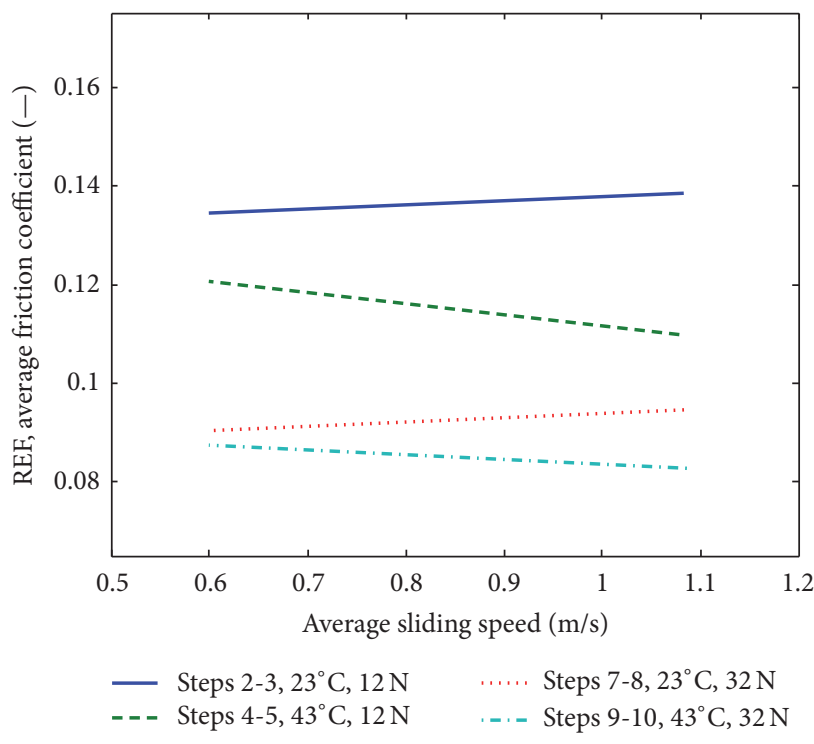

(a)

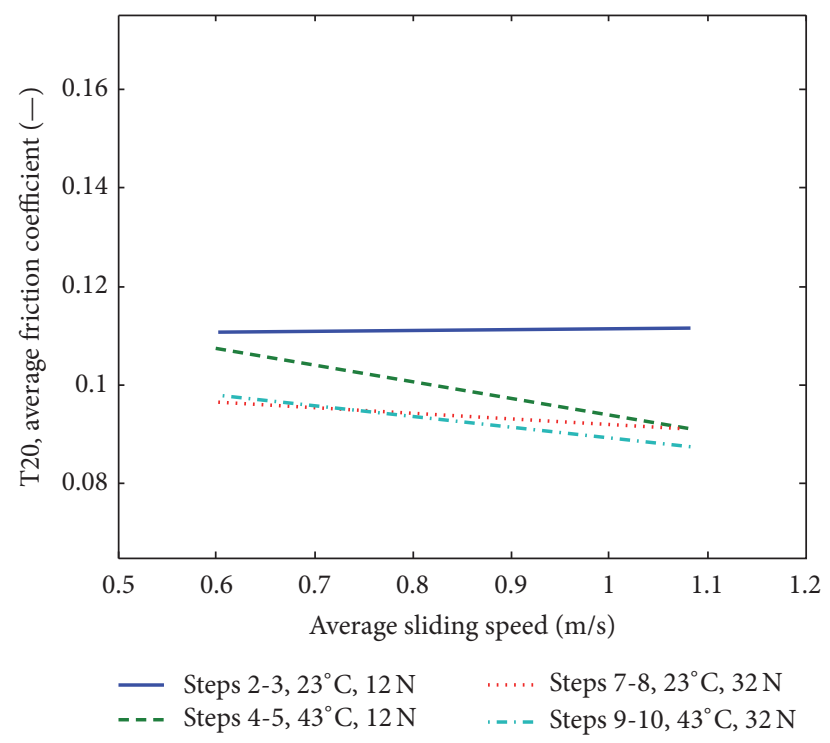

(b)

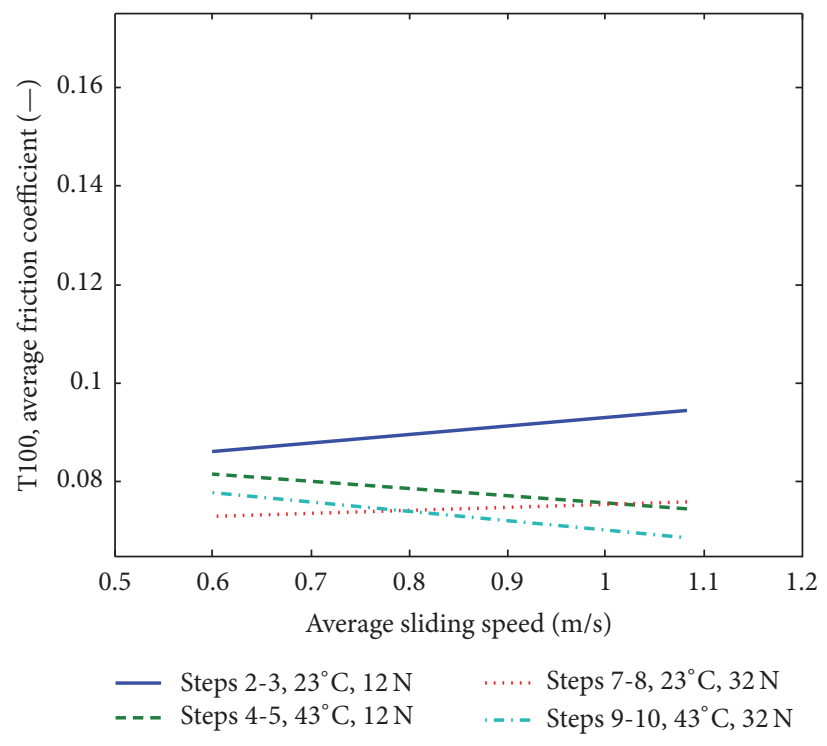

(c)

FIGURE 12: Evaluation of the different levels of DoE input parameters. The effect of sliding speed on the friction coefficient. (a) REF. (b) T20. (c) T100.

flow profile is small; however, for application in an engine, the flow profile dependency of texture geometry needs to be further investigated.

Manufacturing a consistent depth of $20 \mu \mathrm{m}$ on T20 samples proved to be difficult; however, these is no reason to suppose from the experimental results that the distribution in depth is important.

4.3. Additional Discussion regarding Experimental Tribometer Setup. The tribometer used in this study was not originally constructed to perform tests with combined high sliding velocity and low levels of load; the result presented in this study is a representative quantification of the hydrodynamic lubrication regime, and, however, it is not possible to study more viscous contact using the presented tribometer without alteration of sample bodies. It is thus suggested that future experiments should be conducted in an experimental device capable of running higher sliding speeds. In an analysis of hydrodynamic friction losses, it could be possible to use an experimental device with constant sliding speed (as opposed to reciprocating, e.g., pin-on-disc, block-on-ring) although in an experimental setup it is important to maintain line contact between the surfaces. 


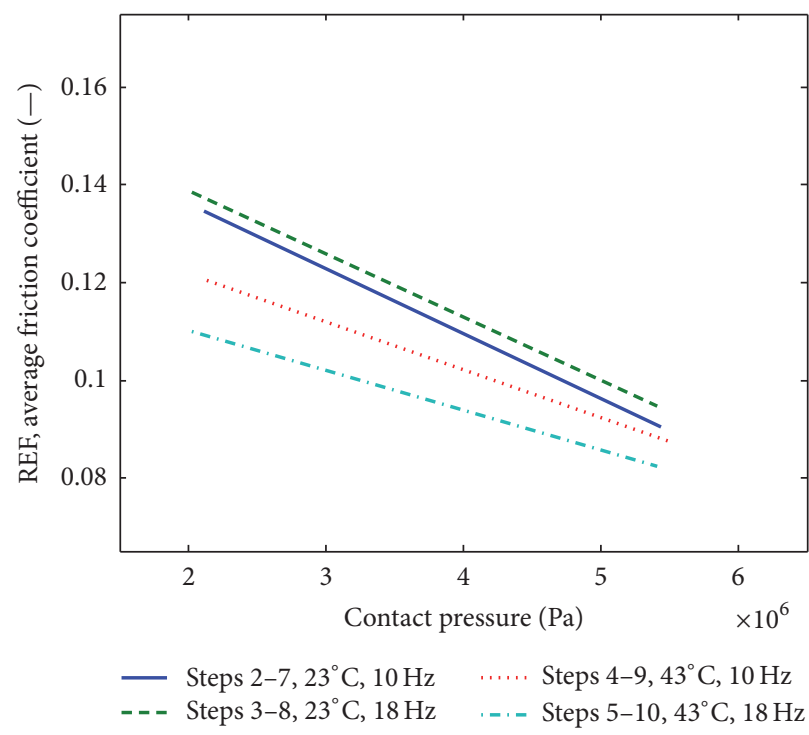

(a)

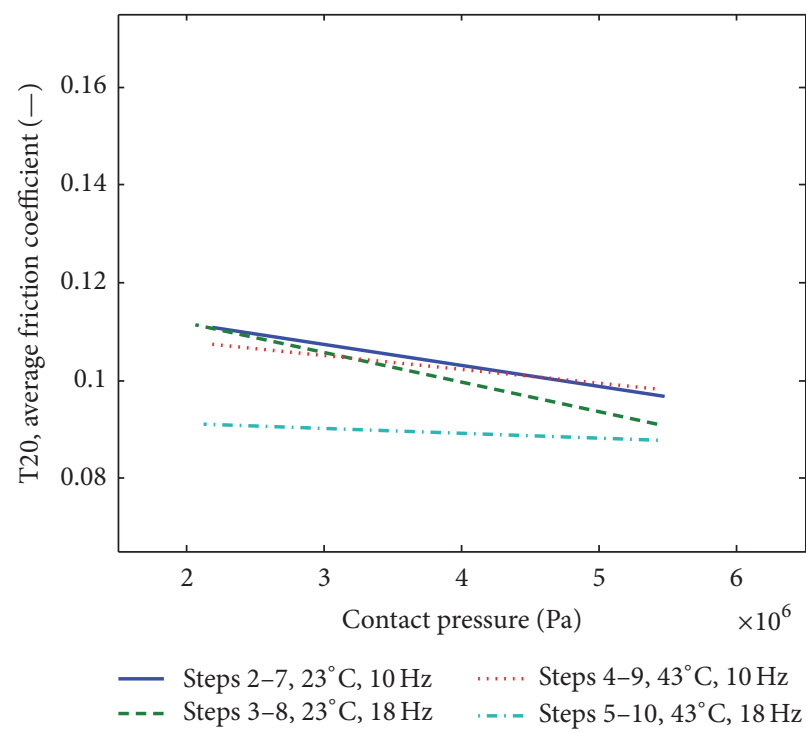

(b)

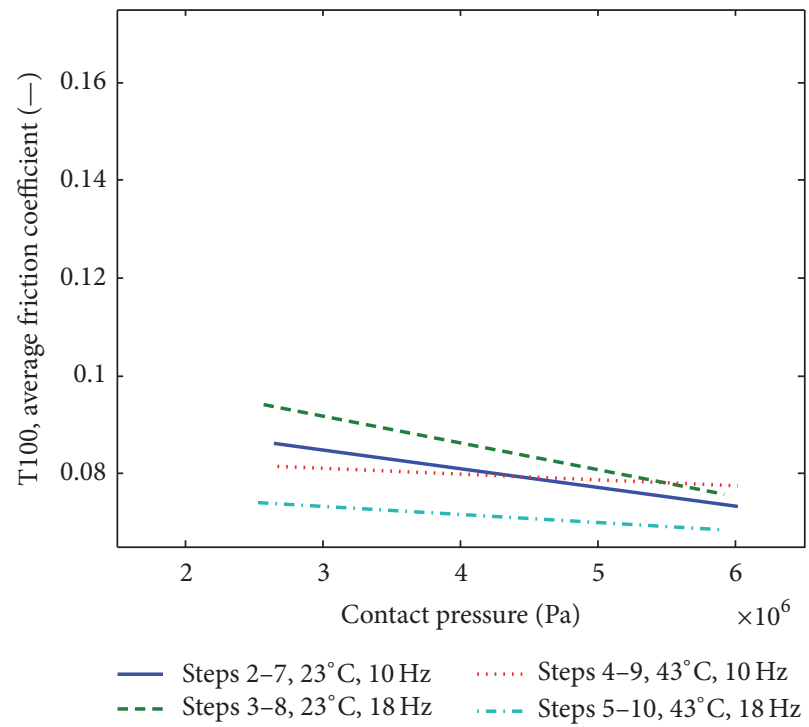

(c)

FIGURE 13: Evaluation of the different levels of DoE input parameters. The effect of contact pressure on the friction coefficient. (a) REF. (b) T20. (c) T100.

\section{Conclusions}

As a means of decreasing hydrodynamic friction losses, two different types of surface textures were analyzed in reciprocating tribometer experiments. The following conclusions can be drawn from this study:

(i) The two types of the investigated textured surfaces are quantified by $3 \mathrm{D}$ profilometry, by which it is shown that the only parameter that differs between the two types is the texture depth.

(ii) The novel type of surface texturing presented in the study decreases friction in the hydrodynamic regime in the contact between oil control ring and cylinder liner.

(iii) The analyzed textured surface does not increase wear; on the contrary, the textured surface exhibits smaller signs of abrasive wear in tribometer experiments; this was due to entrapment of wear particles in textures.

(iv) In further discussions, it is here suggested that the hydrodynamic frictional losses between the cylinder liner and the piston ring can be greatly reduced by the following design of a textured cylinder liner:

(a) The amplitude of the plateau surface on the complete axial length of a textured cylinder 
TABLE 4: The table shows a complete overview of the measured dimensions of the textured samples.

(a)

\begin{tabular}{lccccccc}
\hline & $\begin{array}{c}\text { Density of grains } \\
(\%)\end{array}$ & $\begin{array}{c}\text { Area } \\
\left(\mathrm{mm}^{2}\right)\end{array}$ & $\begin{array}{c}\text { Area st. dev. } \\
\left(\mathrm{mm}^{2}\right)\end{array}$ & $\begin{array}{c}\text { Perimeter } \\
(\mu \mathrm{m})\end{array}$ & $\begin{array}{c}\text { Perimeter st. dev. } \\
(\mu \mathrm{m})\end{array}$ & $\begin{array}{c}\text { Orientation } \\
\left({ }^{\circ}\right)\end{array}$ & $\begin{array}{c}\text { Orientation st. dev. } \\
\left({ }^{\circ}\right)\end{array}$ \\
\hline T20-1 & 32,2223 & 4,34707 & 0,0397027 & 8265,17 & 65,4723 & 159,4 & 1,25886 \\
T20-2 & 32,8645 & 4,29443 & 0,147231 & 8277,15 & 358,444 & 158,529 & 6,6634 \\
T20-3 & 33,8209 & 4,42867 & 0,0774429 & 8403,61 & 386,756 & 159,292 & 4,49348 \\
T20-4 & 32,9664 & 4,42515 & 0,0374976 & 8304,15 & 62,9534 & 159,532 & 0,925686 \\
T100-1 & 33,5814 & 4,39362 & 0,0402664 & 8303,7 & 67,3321 & 160,107 & 0,890755 \\
T100-2 & 34,0799 & 4,44955 & 0,114732 & 8378,44 & 239,861 & 159,644 & 2,18038 \\
T100-3 & 34,1404 & 4,44813 & 0,105916 & 8381,69 & 161,312 & 159,602 & 1,83101 \\
T100-4 & 31,5613 & 4,42882 & 0,0626995 & 8332,02 & 99,071 & 159,907 & 1,58551 \\
\hline
\end{tabular}

(b)

\begin{tabular}{lcccccc}
\hline & $\begin{array}{c}\text { Min. diameter } \\
(\mu \mathrm{m})\end{array}$ & $\begin{array}{c}\text { Min. diameter st. dev. } \\
(\mu \mathrm{m})\end{array}$ & $\begin{array}{c}\text { Max. diameter } \\
(\mu \mathrm{m})\end{array}$ & $\begin{array}{c}\text { Max. diameter st. dev. } \\
(\mu \mathrm{m})\end{array}$ & $\begin{array}{c}\text { Depth } \\
(\mu \mathrm{m})\end{array}$ & $\begin{array}{c}\text { Depth st. dev. } \\
(\mu \mathrm{m})\end{array}$ \\
\hline T20-1 & 1896,47 & 9,35645 & 2910 & 8,40168 & 19,59715882 & 6,337111655 \\
T20-2 & 1872,57 & 11,0435 & 2917,71 & 121,281 & 18,16972941 & 4,905834966 \\
T20-3 & 1912 & 5,75698 & 2947,43 & 81,393 & 22,64912941 & 7,889610536 \\
T20-4 & 1915,29 & 6,52384 & 2926,18 & 7,67529 & 19,46122353 & 3,674416624 \\
T100-1 & 1909,43 & 7,53766 & 2905,71 & 9,34596 & 94,58104412 & 13,81767236 \\
T100-2 & 1919,71 & 6,08779 & 2930 & 103,178 & 87,75976176 & 11,92867327 \\
T100-3 & 1919,14 & 6,03392 & 2928,29 & 73,4647 & 97,93557647 & 13,59051635 \\
T100-4 & 1917,94 & 6,76471 & 2915,59 & 18,8166 & 87,18046471 & 11,65203976 \\
\hline
\end{tabular}

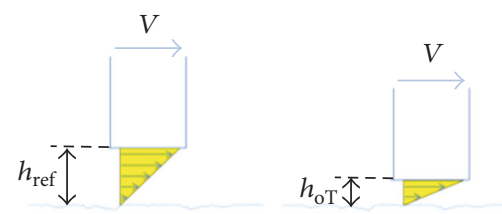

(a)

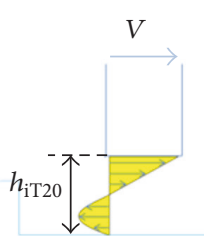

(b)

FIGURE 14: Schematic overview of the oil film build-up for the reference surface (a) and piston ring passage over the plateau of a textured surface; the piston ring passage over a $20 \mu \mathrm{m}$ deep texture and the piston ring passage over a $100 \mu \mathrm{m}$ deep texture (b).

liner is minimized to keep boundary friction at minimum.

(b) Texturing is applied on the part of the axial length on the cylinder liner below the upper reversal zone and above the lower reversal zone. The area density of texturing increases at midstroke position and decreases towards the reversal zones.

(c) The reversal zones remain untextured; there are two main reasons for this; firstly, the sliding speed is low in the vicinity of the reversal zones and thus the hydrodynamic friction is low; secondly, the introduction of textures with relatively large geometry might increase wear.

\section{Appendix}

See Tables 4(a) and 4(b). 

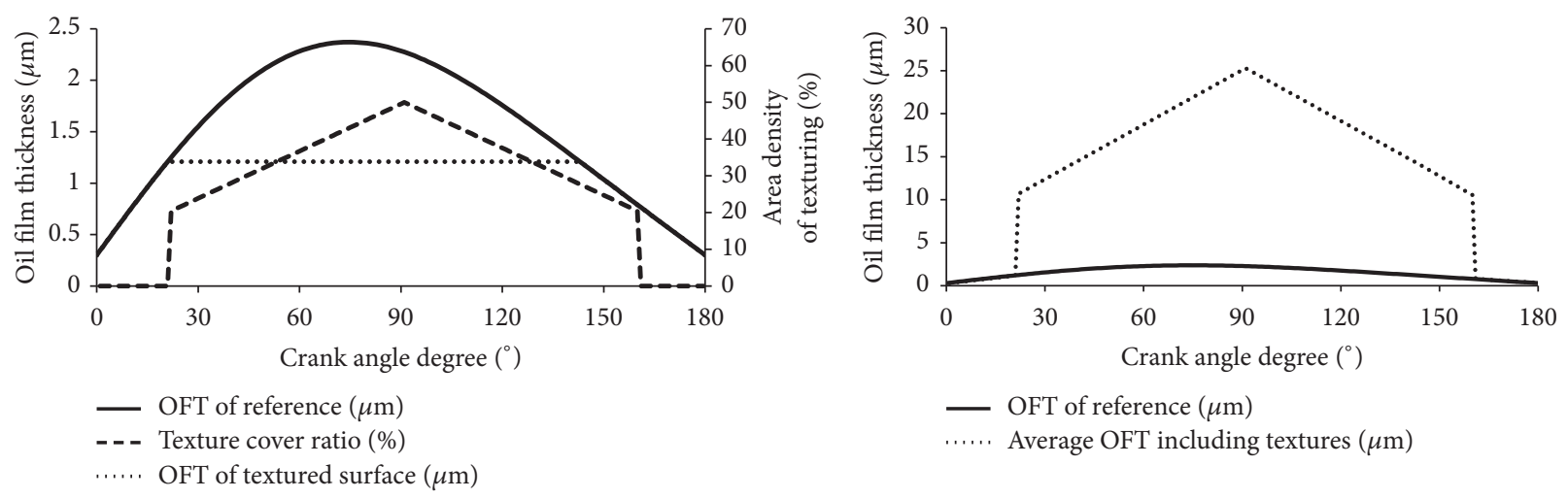

FIGURE 15: Tentative example of the oil film thickness with textured cylinder liner surfaces.

\section{Conflicts of Interest}

The authors declare that they have no conflicts of interest.

\section{References}

[1] J. B. Heywood, Internal Combustion Engine Fundamentals, McGraw-Hill, New York, NY, USA, 1988.

[2] R. I. Taylor, "Heavy duty diesel engine fuel economy: lubricant sensitivities," in Proceedings of the International Spring Fuels \& Lubricants \& Exhibition, Paris, France, June 2000.

[3] D. E. Richardson, "Review of power cylinder friction for diesel engines," Journal of Engineering for Gas Turbines and Power, vol. 122, no. 4, pp. 506-519, 2000.

[4] M. Nakada, "Trends in engine technology and tribology," Tribology International, vol. 27, no. 1, pp. 3-8, 1994.

[5] E. Tomanik, "Friction and wear bench tests of different engine liner surface finishes," Tribology International, vol. 41, no. 11, pp. 1032-1038, 2008.

[6] J. Li, D. Xiong, J. Dai, Z. Huang, and R. Tyagi, "Effect of surface laser texture on friction properties of nickel-based composite," Tribology International, vol. 43, no. 5-6, pp. 1193-1199, 2010.

[7] P. Andersson, J. Koskinen, S. Varjus et al., "Microlubrication effect by laser-textured steel surfaces," Wear, vol. 262, no. 3-4, pp. 369-379, 2007.

[8] S. Yuan, W. Huang, and X. Wang, "Orientation effects of microgrooves on sliding surfaces," Tribology International, vol. 44, no. 9, pp. 1047-1054, 2011.

[9] S. Johansson, C. Frennfelt, A. Killinger, P. H. Nilsson, R. Ohlsson, and B. G. Rosén, "Frictional evaluation of thermally sprayed coatings applied on the cylinder liner of a heavy duty diesel engine: pilot tribometer analysis and full scale engine test," Wear, vol. 273, no. 1, pp. 82-92, 2011.

[10] S. Johansson, P. H. Nilsson, R. Ohlsson, and B.-G. Rosén, "Simulation and experimental analysis of the contact between oil control ring and cylinder liner in a heavy duty diesel engine," in Proceedings of the 18th International Colloquium Tribology, Stuttgart, Germany, January 2012.

[11] M. Priest and C. M. Taylor, "Automobile engine tribology-approaching the surface," Wear, vol. 241, no. 2, pp. 193203, 2000.

[12] H. Moritani, H. Tokoro, M. Tohyama et al., "Challenge to the diesel engine lubrication with fuel," SAE Technical Paper 200701-1978, SAE International, 2007.
[13] Y. Wakuri, T. Hamatake, M. Soejima, and T. Kitahara, "Piston ring friction in internal combustion engines," Tribology International, vol. 25, no. 5, pp. 299-308, 1992.

[14] Y. Qiu and M. M. Khonsari, "Experimental investigation of tribological performance of laser textured stainless steel rings," Tribology International, vol. 44, no. 5, pp. 635-644, 2011.

[15] S.-W. Cho, S.-M. Choi, and C.-S. Bae, "Frictional modes of barrel shaped piston rings under flooded lubrication," Tribology International, vol. 33, no. 8, pp. 545-551, 2000.

[16] H. L. Costa and I. M. Hutchings, "Hydrodynamic lubrication of textured steel surfaces under reciprocating sliding conditions," Tribology International, vol. 40, no. 8, pp. 1227-1238, 2007.

[17] B. Podgornik, L. M. Vilhena, M. Sedlaček, M. R. Ripoll, Z. Rek, and I. Zun, "Effectiveness of surface texturing in different lubrication regimes," in Proceedings of the 14th Nordic Symposium on Tribology (NORDTRIB '10), Storforsen, Sweden, 2010.

[18] S. Johansson, P. H. Nilsson, R. Ohlsson, and B.-G. Rosén, "Experimental friction evaluation of cylinder liner/piston ring contact," Wear, vol. 271, no. 3-4, pp. 625-633, 2011.

[19] S. Johansson, A surface engineering approach to reduction of frictional losses of heavy duty diesel engines [Ph.D. thesis], Chalmers University of Technology, 2012.

[20] M.-S. Suh, Y.-H. Chae, S.-S. Kim, T. Hinoki, and A. Kohyama, "Effect of geometrical parameters in micro-grooved crosshatch pattern under lubricated sliding friction," Tribology International, vol. 43, no. 8, pp. 1508-1517, 2010.

[21] L. L. Ting, "Development of a reciprocating test rig for tribological studies of piston engine moving components-part II: measurements of piston ring friction coefficients and rig test confirmation," in Proceedings of the International Congress \& Exposition, SAE 930686, Detroit, Mich, USA, March 1993.

[22] P. Andersson, "A new tribometer for piston ring friction measurements," Tribological Research and Design for Engineering Systems, vol. 41, pp. 501-510, 2003.

[23] H. Chen, J. Li, D. Chen, and J. Wang, "Study of the effect of transverse and longitudinal surface patterns on drag-reduction in shear-thinning fluid," Proceedings of the Institution of Mechanical Engineers Part J: Journal of Engineering Tribology, vol. 221, no. 2, pp. 87-94, 2007.

[24] M. Knopf, C. Eiglmeier, and G. P. Merker, "Calculation of unsteady hydrodynamic lubrication and surface contact at the piston-ring/cylinder-liner interface," in Proceedings of the International Spring Fuels and Lubricants Meeting and Exposition, Dearborn, Mich, USA, May 1998. 
[25] J. A. Greenwood, "Constriction resistance and the real area of contact," British Journal of Applied Physics, vol. 17, no. 12, pp. 1621-1632, 1966.

[26] H.-J. Jordan, "Optical chromatic confocal probes," in Proceedings of the 12th International Colloquium on Surfaces, Chemnitz, Germany, January 2008.

[27] A. Kovalchenko, O. Ajayi, A. Erdemir, and G. Fenske, "Friction and wear behavior of laser textured surface under lubricated initial point contact," Wear, vol. 271, no. 9-10, pp. 1719-1725, 2011.

[28] T. Hegemier and M. Stewart, "Some effects of liner finish on diesel engine operating charateristics," in Proceedings of the International Congress and Exposition, Detroit, Mich, USA, March 1993.

[29] Y. Tateishi, "Tribological issues in reducing piston ring friction losses," Tribology International, vol. 27, no. 1, pp. 17-23, 1994.

[30] T. Seki, K. Nakayama, T. Yamada, A. Yoshida, and M. Takiguchi, "Study on variation in oil film thickness of a piston ring package: variation of oil film thickness in piston sliding direction," JSAE review, vol. 21, no. 3, pp. 315-320, 2000.

[31] $\mathrm{H}$. Wu, "An analysis of the engagement of wet-clutch plates," Wear, vol. 24, no. 1, pp. 23-33, 1973.

[32] P. Payvar, "Laminar heat transfer in the oil groove of a wet clutch," International Journal of Heat and Mass Transfer, vol. 34, no. 7, pp. 1791-1798, 1991. 


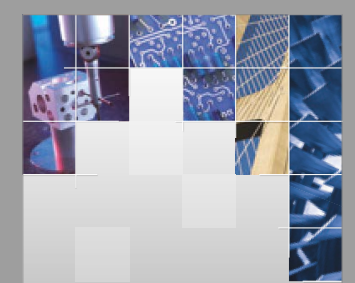

\section{Enfincering}
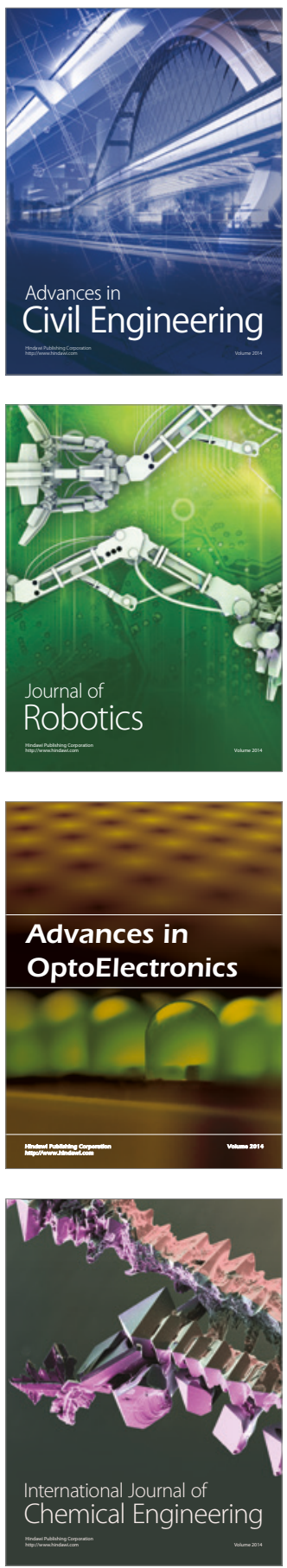

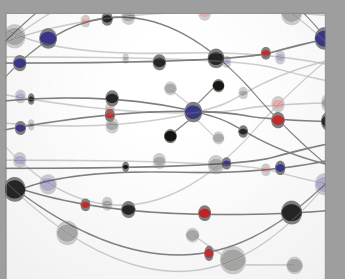

The Scientific World Journal

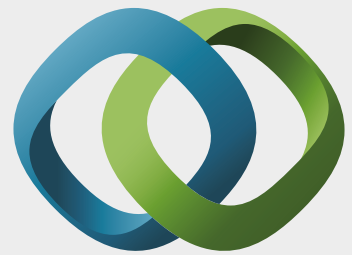

\section{Hindawi}

Submit your manuscripts at

https://www.hindawi.com
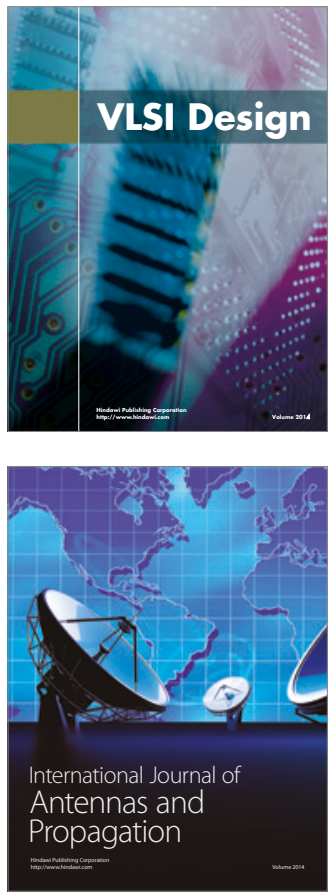

\section{Rotating}

Machinery
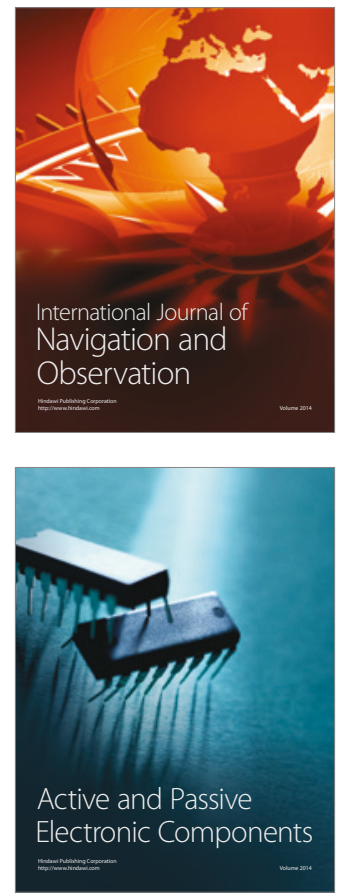
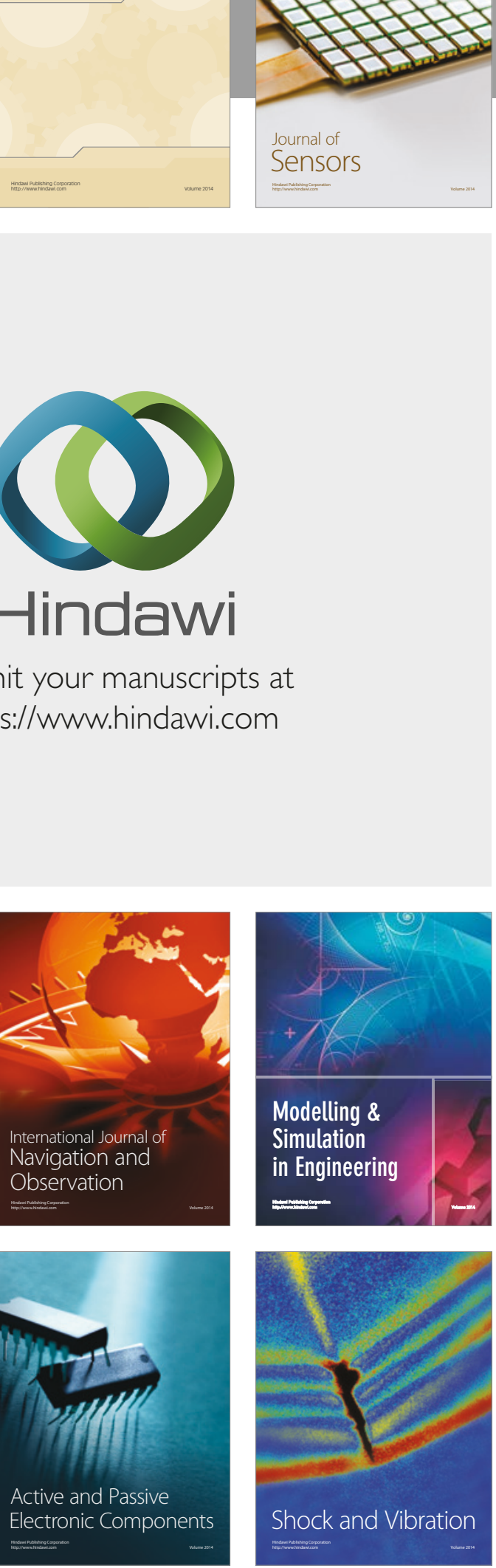
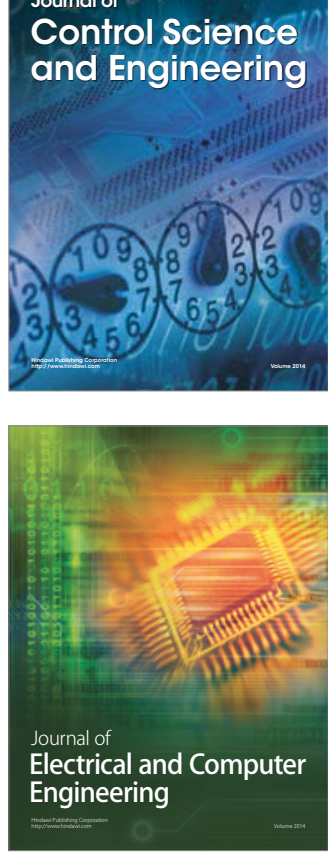

Distributed

Journal of

Control Science

and Engineering
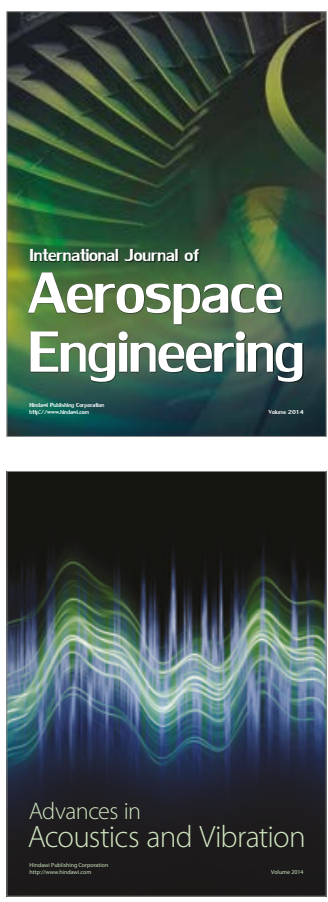

Sensor Networks 